\title{
CAN WELFARE ABUSE BE WELFARE IMPROVING?
}

\author{
Karol Mazur*
}

\begin{abstract}
In this paper, I analyze quantitatively a model of labor search with unemployment insurance (UI), savings, voluntary quits and various labor attachment requirements. In particular, I study welfare consequences of a powerful reform giving UI entitlement to workers quitting their jobs voluntarily in order to search for another one. Results of the model calibrated to the US labor market show that there are significant welfare gains associated with pursuing a generous entitlement policy for quitters as compared to the US status-quo. Moreover, I employ the assumption of monetary search costs and show that it can explain the empirically documented unemployed worker search behavior. Finally, by inducing different unemployment benefit eligibility requirements, the model identifies a concrete policy that could help us understand differences in the unemployment rate, match quality and income inequality between the US and Europe.
\end{abstract}

Key words: Unemployment Insurance, Labor Search, Voluntary Quits, Savings, Search Behavior

JEL: J64, J65, J68

${ }^{*}$ Department of Economics, European University Institute, Via della Piazzuola 43, I-50133 Firenze, Italy. Contact: k.mazur@eui.eu 


\section{Introduction}

In the late 1970s the labor markets in the US and Europe began to diverge and these differences are profoundly visible until today. Unsurprisingly, this contrasting evolution has attracted interest of many economists. Among many topics related to it, arguably the most attention has been devoted to unemployment insurance (UI) systems (vide e.g. the research program ran by Ljungqvist and Sargent). In this paper, I model one particular aspect of UI which differs strikingly between the two continents: the benefit entitlements for workers quitting jobs voluntarily. While in the US no quitter is eligible for receiving unemployment benefits ${ }^{1}$, the entitlement policy in Europe is generally more generous and usually allows for payment of benefits in such cases subject to some sanctions. The exact requirements and sanctions have been described by Venn (2012). In general, there is a fixed work experience (or rather a social security contribution) requirement which is the same for both fired workers and quitters - usually it varies between 6 to 18 months of employment within the last 12-36 months preceding unemployment. On top of it, in order to discourage quitting, there are sanctions ${ }^{2}$ in form of payment suspensions: in Lithuania and Slovakia there are no such sanctions, in Denmark there is a 3-week sanction, in Austria - 4; in Belgium - 7; in Sweden 9; in Germany - 12. Nevertheless, there are also European countries not paying out the benefits for voluntarily unemployed, like Estonia, Italy or the Netherlands. To the best of my knowledge, there is no research analyzing the welfare effects of these policy choices. This paper is trying to fill this gap.

To this extent, I construct and calibrate to the US labor market a job search model where fired workers are eligible for time-limited UI and ask what is the optimal entitlement policy for voluntarily unemployed, i.e. whether such quits should be punished by no UI entitlement or, if not, for how long should such workers be employed before being awarded UI entitlement. In order to pick the best policy I perform a social welfare analysis. This is a natural approach as it requires a consistent accounting for both benefits (such as more time and resources available for job search) and adverse incentive effects of the UI (such as workers being more picky, generating possibly higher unemployment rate and consequently higher tax rate to finance the welfare system).

In particular, when an ex-ante homogenous worker becomes unemployed she con-

\footnotetext{
${ }^{1}$ Some states in the US allow quitters to apply for benefits if backed with a "good cause". Nevertheless, as Venn (2012) reports, most (including e.g. the seven largest states where almost $50 \%$ of the U.S. population lives) do disqualify all the voluntary quits.

${ }^{2}$ These sanctions are often not executed if the employer does not contest worker's UI claim.
} 
sumes her savings or unemployment benefits (defined as the replacement ratio tied to her most recent wage). Furthermore, in order to find a job, she exercises costly search effort. The search effort is random meaning that although the expected wage offer is increasing in amount of the search effort exercised, some unemployed are luckier and receive higher wage offers than others. Consequently, workers set optimally their reservation wages and reject all the wage offers below it. Moreover, some employed workers find it optimal to behave opportunistically and quit their jobs. Thus, workers become ex-post heterogenous with respect to their employment status, wage income received and savings.

The latter means that there are some jobs in the economy which workers enter solely in order to build up their saving accounts and (if the policy allows for it) regain eligibility for the benefits, quit the job short after and search for a better one thereafter. I refer to this opportunistic behavior as a welfare abuse since if the search effort was perfectly observable, workers would clearly exercise a higher effort and so in such a case the policy of entitlement for quitters might be unnecessary. Consequently, this moral hazard related behavior results in an excessive use of the welfare system and thus a higher tax burden on employed workers.

In fact, there is evidence that workers do behave as predicted by the model employed in this paper. First of all, although quitters in the US are not entitled to the UI, on average $10 \%$ of unemployed workers are job leavers (according to the CPS data set). Moreover, Christofides and McKenna (1996) studied data from Canadian Longitudinal Labour Market Activity Survey for 1986/87 and found a significant increase in the job separation probability in the week right after a worker satisfies unemployment benefit eligibility. This finding was later confirmed by Green and Riddell (1997) and Baker and Rea (1998) who studied the same data for the year 1990. Similarly, Jurajda (2002) studied the US labor market and found that entitlement for unemployment insurance significantly increases the probability of a lay-off. Importantly, these studies do not look explicitly at voluntary quits. Nevertheless, given that we should not always blindly believe in a dichotomy between lay-offs and voluntarily quits (as discussed for example by Feldstein (1976)), it is surely possible for many quitters to pass themselves off as being fired. However, it also seems very reasonable that there is still a significant share of quits due to personal reasons of the employees (especially in labor markets where quitters receive benefits). In what follows, I am modeling the latter phenomenon where there is a clear distinction between the two groups.

Furthermore, in the model presented below workers behave opportunistically in 
order to improve upon the match quality. Indeed, Tatsiramos (2009) presents empirical evidence for the role of unemployment insurance in correcting the misallocations in labor markets: he finds that for workers entitled to receiving benefits the subsequent employment spells are longer and that this relationship is more profound in countries with relatively more generous welfare systems.

Results suggest that, in spite of the associated fiscal costs in form of a higher unemployment rate and so a higher tax rate, the optimal policy is characterized by entitlement to UI for quitters. In particular, pursuing a generous entitlement policy leads to long run welfare gains equivalent to $4.38 \%$ of life time consumption. Importantly, these results should be robust to the possibility of quitters passing themselves off as being laid-off, as surely not every worker is able to do this and as firing a worker is associated with non-negligible firing costs (for example in the US the unemployment insurance tax is experience rated). The intuition for the result is two-fold. Firstly, as already mentioned, the policy allows for average match quality improvement. It does so by reducing the income risk associated with quitting a job in order to look for a better one. Secondly, it extracts many long-term unemployed into employment by increasing the non-wage value of low paid jobs and so by lowering the reservation wage of those workers.

Interestingly, the results of the model also suggest that the policy studied here may be a force pushing characteristics of the US labor market towards the European one. Firstly, following the optimal policy generates a higher unemployment rate. This is due to the fact that next to fired workers, the policy increases the mass of voluntarily unemployed ones. Secondly, it reduces both the pre- and after-tax income inequality (i.e. there is no efficiency-equity trade-off). This is due to two effects induced by the entitlement policy: (1) a significant reduction in mass of unemployed on social assistance; and (2) an increase in the budget balancing tax rate bringing the income of employed individuals closer to the income of unemployed. Thirdly, the average match quality post-reform is higher, in line with evidence in Manacorda and Petrongolo (1999) that the labor market mismatch has grown much faster in the US as compared to Europe.

Moreover, I investigate the assumption of monetary (or non-separable) search costs which is mostly ignored in the literature. Results show that this assumption is able to generate the empirically documented spike in search effort at the benefit exhaustion. Furthermore, it also generates an initial decrease in search effort at the beginning of unemployment spell - in line with the recent evidence in Faberman and Kudlyak (2016). 
On the other hand, as is already acknowledged in the literature (see e.g. Krueger and Mueller (2010)), the usually employed in the literature assumption of separable search costs does not deliver such features. Significantly, as opposed to the latter assumption, increasing generosity of unemployment benefits in the model with monetary search costs does not necessarily decrease the search effort. Finally, the model generates important testable implications about differences in search effort and reservation wage behavior, and so in labor market outcomes for similar workers differing only with respect to their financial wealth.

My paper builds on a long literature of unemployment insurance. While the most common rationale for the payment of unemployment benefits is to provide risk averse workers with income insurance allowing for consumption smoothing, there is also a smaller strand of research work starting with Burdett (1979) which does not see the unemployment insurance solely as a serious distortion but rather argues for the role of insurance as a subsidy to search. In this literature the role of unemployment insurance is not only to give unemployed the time and resources to find a job but also to find the right one, i.e. it allows the workers to improve upon the quality of matches in labor markets. In this paper, I argue for a similar role of unemployment insurance.

While searching for reasons of labor markets divergence, Ljungqvist and Sargent (1998) argued that although in times of low micro-economic labor volatility the presence of unemployment insurance system has moderate impact on the unemployment rate, the systems which are relatively more generous may have a much more profound effect on the number of unemployed in times of high turbulence. In a more recent contribution, Kitao, Ljungqvist and Sargent (2015) explain this divergence with higher minimum wages in Europe and human capital depreciation during unemployment. On the other hand, Marimon and Zilibotti (1999) used a model with both heterogenous workers and firms, search frictions and skilled-biased technological change coupled with the assumption of complementarity between capital and capital-specific-skills to show that the differences in generosity of unemployment systems may account for the observed discrepancies between the US and European labor markets. In particular, they showed that although upon the technology-specific shock the economy with more generous unemployment welfare system has a higher unemployment rate, it is characterized by a higher quality of matches, i.e. a higher growth of productivity per worker and a relatively lower wage inequality - a result complementary to the one in Ljungqvist and Sargent (1998). In this work, I identify a concrete real world policy which may be a channel of effects similar to these described in Marimon and Zilibotti (1999). 
As I assume perfect distinction between lay-offs and quits, this paper is complementary to Hopenhayn and Nicolini (2009) where they derived an optimal unemployment insurance design under assumption that principal cannot distinguish quits from lay-offs. This assumption generates an opportunistic worker behavior similar to the one imputed in my paper. Their conclusion is that under the latter assumption the optimal contract involves conditioning of the benefit eligibility on worker's employment history.

Furthermore, the result of no efficiency-equity trade-off derived in this model is analogous to the one reached by Acemoglu and Shimer (1997) in a general equilibrium search setup. In their model, unemployment insurance induces risk averse workers to seek higher paying jobs with higher unemployment risk and so also induces firms to invest into higher paying technologies. In other words, the unemployment insurance increases both the output and improves the risk sharing.

Finally, Aguiar, Hurst and Karabarbounis (2013) and other authors mentioned therein argued that modeling consumption and leisure in a non-separable way is important for explaining a wide variety of macroeconomic observations in business cycle models. Thus, the differences in the worker behavior generated by the two assumptions are complementary to this literature and suggest that the same is also true when it comes to explaining workers' search behavior.

This paper is organized as follows. The next section outlines the theoretical model together with measures used for evaluating the policy experiments. In Section 3, I calibrate the model to the US labor market. Section 4 discusses the results. Finally, Section 5 concludes.

\section{The Model Economy}

The economy consists of a continuum of ex-ante identical, risk-averse, infinitely-lived agents with measure normalized to 1 . Workers have access to risk-less saving accounts and UI system. Time is discrete and in every period an unemployed worker receives with some probability a wage draw. This probability depends on the amount of random search effort chosen by the worker. After the draw, she has to decide whether to accept the job or not. Employed workers make a decision about quitting or staying on the job.

\section{$2.1 \quad$ Workers}

Working does not yield disutility. Any worker can be either unemployed or employed and is maximizing her discounted life-time utility with respect to (1) savings $a$, the 
level of unobservable random search effort required to find the job $q$ (when unemployed only, i.e. there is no on the job search - see the discussion of this assumption in Section 4.4) and then, if she draws a wage offer from some distribution, whether to accept it; or (2) savings $a$ and the decision about staying on the job or quitting it in order to search for another. When employed she faces a risk of an exogenous separation happening at the Poisson rate $\sigma$.

Workers have a common instantaneous utility function $U(c)$ satisfying $U^{\prime}(c)>0$, $U^{\prime \prime}(c)<0$ and an Inada condition at zero. When unemployed they exercise search effort $q$ which is subject to convex costs (entering directly the utility function) given by $g(q)=$ $\alpha q^{\zeta}$, where $q \in[0,1]$. The mapping from worker's effort to the effective transition probability is governed by an identity function $f(q)=q$. Importantly, searching is unobservable giving rise to standard moral hazard of suboptimal search effort.

In each period an unemployed individual faces a stochastic employment opportunity: either she is offered a job opportunity for wage $w$ or not. There are $n$ different wage offers that the worker may draw and their support is on the $[0,1]$ interval. Denote this wage distribution by $\mathrm{F}$. To explain this heterogeneity in wages, just think of $n$ different technologies and of many firms having access solely to one of them. Also, I assume that the wage rate received by an employed worker is constant over time. Finally, monitoring of job applicants is impossible and therefore a worker who rejects a work opportunity continues to receive unemployment benefits according to her benefit payment path (for description of UI see Section 2.2).

Apart from the UI, workers have access to risk-less saving accounts with a constant rate of return $r$. Considering this channel is important as it allows workers to selfinsure against the state of unemployment and so it may have some first-order effects on the worker's search and offer acceptance behavior (and so on all the other equilibrium outcomes). ${ }^{3}$

Importantly, I assume that the cost of search effort is in terms of consumption, i.e. worker's utility function is of the form $U(c-g(q))$. In this model, the role of unemployment benefits is not only to insure workers against the state of unemployment but also to provide them with a subsidy to search so that they can find the right job. Notice that this formulation introduces wealth and substitution effects between consumption and search effort. In particular, workers 1) increase their search effort if the wealth effect dominates; or 2) reduce it (in order to smooth consumption) if the

\footnotetext{
${ }^{3}$ See e.g. Abdulkadiroglu, Kuruscu and Sahin (2002) for discussion of the role of self-insurance for welfare conclusions.
} 
substitution effect dominates. The wealth effect is especially strong right before the benefit exhaustion. At that moment workers want to avoid falling into the badly paid state of social assistance implying a significant increase in probability of a long-term unemployment lock-in (see Section 4 for a detailed discussion).

Moreover, this assumption is realistic in two ways. First of all, searching for a job costs money as well as time or physical effort. Any unemployed worker that wants to find a job has to buy and maintain a suit, travel for an interview, send out applications on nice paper or get some professional training. Secondly, many consumption expenditures such as a comfortable car or a home computer with internet access are complementary to job search. Such a modeling assumption was employed solely for tractability with CARA utility by Werning (2001) and also by Shimer and Werning (2007).

Significantly, the mechanics generated by the assumption of monetary search costs employed here are supported by the empirical evidence documented by Blau and Robins (1990), Wadsworth (1991) and more recently by Krueger and Mueller (2014) who found that unemployed workers eligible for unemployment compensation search more actively than those not eligible. Similarly, as already mentioned, the assumption generates a spike in search effort at the benefit exhaustion. Nevertheless, there are results speaking against the monetary search cost as for example Jones (1989) or Krueger and Mueller (2010) who find that higher benefits reduce the time devoted to search among benefit recipients. However, with unemployment benefits defined as a replacement ratio, such a behavior could stem from the fact that workers receiving higher benefits (and so having worked in better jobs) find themselves in a more favorable search environment not requiring that much of a time investment (e.g. due to knowing well connected people).

Finally, note that typically in the literature search effort is modeled using the separable utility function of the form $U(c)-g(q)$, which can be interpreted in terms of physical effort. Since there is no research on the degree of substitutability of money and time devoted to job search (in the extreme think of wealthy individuals employing headhunters), both should be seen as reasonable modeling assumptions. Therefore, for comparability with other papers and exposition of the dynamics induced by the two assumptions, I also investigate all the results in the model with separable search cost. As I discuss in Sections 3 and 4, such a model is not able to match the time profile of search effort documented empirically. In particular, it cannot generate search effort spike at the benefit exhaustion. On the other hand, the monetary cost of search can fully explain this behavior. 


\subsection{Unemployment System}

The design of the unemployment insurance system together with search frictions and exogenous separations are the source of ex-post heterogeneity among the workers. It is financed with linear taxes raised by the government running a balanced budget. The tax distorts the decision about the search effort chosen. Any unemployed worker whose match was separated exogenously qualifies for benefits. Note that below I calibrate the model to the exogenous separation probability of 0.1 quarterly. This implies that in expectation workers are fired once in 2.5 years. This work experience satisfies labor attachment requirement in virtually every country.

The worker who decides to quit the job voluntarily is eligible for benefits if she had worked in her last job for at least $\hat{T}$ periods (policy experiment parameter); otherwise she receives the social assistance income $i_{S A}$. The latter value is also financed by the government and pins down the value of worker's outside option. Any unemployed and eligible worker receives the value of $b=\gamma w$ for $T$ periods, where $w$ is the worker's most recent wage. From period $T$ onwards, she receives the income of $i_{S A}$ until she finds a new job.

\subsection{Recursive Formulation}

Given Sections 2.1 and 2.2, each worker's current state can be captured with a vector $s=(a, t, w, x)$ of four state variables:

1. Amount of savings $a$ in worker's account.

2. Worker's most recent ${ }^{4}$ wage $w \in\left\{w_{1}, \ldots, w_{n}\right\}$.

3. Worker's current employment status $x$ : if employed $x=\mathrm{e}$, or if unemployed $x=\mathrm{u}$.

4. Time $t$ spent in current stage. Notice that for unemployed workers after the drop in the benefit schedule from high to low, i.e. in period $T+1$, the environment becomes stationary due to the benefit schedule being constant from that point onwards. A similar argument applies to the employed workers. Therefore, $t \in$ $\{1,2, \ldots, \max \{\hat{T}, T+1\}\}$. In particular, if a worker has been employed for $t<$ $\hat{T}$ periods and decides to quit, she immediately jumps from the state $(a, t, w, e)$ to the low benefit state $(a, T+1, w, u)$. However, if a match is separated exogenously

\footnotetext{
${ }^{4}$ This state variable also captures the current wage of employed workers.
} 
or endogenously after at least $\hat{T}$ periods on the job, then the unemployed worker is entitled to benefits, i.e. she lands in the state $(a, 1, w, u)$.

Therefore, the following Bellman equations hold for unemployed and employed workers:

$$
\begin{aligned}
V_{u}(a, t, w) & =\max _{\mathrm{a}^{\prime}, \mathrm{q}}\left\{U\left(b(t, w)+(1+r) a-a^{\prime}-g(q)\right)\right\} \\
& +\max _{\mathrm{a}^{\prime}, \mathrm{q}}\left\{f(q) \beta \sum_{w^{\prime}} \max \left\{0, V_{e}\left(a^{\prime}, 1, w^{\prime}\right)-V_{u}\left(a^{\prime}, t^{\prime}, w\right)\right\} \mathbb{P}\left(w^{\prime}\right)+\beta V_{u}\left(a^{\prime}, t^{\prime}, w\right)\right\}
\end{aligned}
$$

where $t^{\prime}=\min \{t+1, T+1\}$.

$$
\begin{aligned}
V_{e}(a, t, w)= & \max _{\mathbf{a}^{\prime}}\left\{U\left((1-\tau) w+(1+r) a-a^{\prime}\right)\right\} \\
& +\max _{\mathbf{a}^{\prime}}\left\{\beta\left(\sigma V_{u}\left(a^{\prime}, 1, w\right)+(1-\sigma) \max \left\{V_{u}\left(a^{\prime}, t^{\prime \prime}, w\right), V_{e}\left(a^{\prime}, t^{\dagger}, w\right)\right\}\right)\right\}
\end{aligned}
$$

where $t^{\prime \prime}=\left\{\begin{array}{ll}1 & \text { if } t=\hat{T} \\ T+1 & \text { if } t<\hat{T}\end{array}, t^{\dagger}=\min \{t+1, \hat{T}\}\right.$

Finally, notice that given the setup, the model possesses the reservation wage property. Given the design of the unemployment system, the reservation wage (just as the effort exerted $q$ ) depends on the three state variables: savings $a$, length of unemployment spell $t$ and last wage $w$.

Proposition (Reservation Wage Property): Consider a worker exercising search effort to find a job in the market described in Section 2.1 and facing unemployment system described in Section 2.2. Then the optimal job search strategy of such a worker has a reservation wage characterization conditional upon worker's current state: the worker will accept a job if and only if the wage draw $w^{\prime}$ is weakly greater than her reservation wage, i.e. $w^{\prime} \geq \bar{w}(a, t, w)$.

Proof. See the Appendix A.

\subsection{Steady State Equilibrium and Government}

In the steady state, the measure of workers in each of the states is constant over time. Let $D_{u}$ and $D_{e}$ be the cross sectional distributions over the states of all the (un)employed workers in the economy and let $d_{u}(a, t, w)$ and $d_{e}(a, t, w)$ be the mass of (un)employed workers currently in a given state with $\sum_{a, t, w}\left(d_{u}(a, t, w)+d_{e}(a, t, w)\right)=1$, i.e. the 
two are the associated probability mass functions. Steady state is characterized by an invariant cross sectional distributions $D^{*}$ (and probabilities $d^{*}$ ) such that $D^{*} \Gamma=D^{*}$, i.e. $D^{*}$ is a left eigenvector for $\Gamma$ with eigenvalue 1.

Moreover, revenue and expenditures of the government have to be balanced in each period. Thus, I close the model with the following condition:

$$
\left[\tau \sum_{a} \sum_{t=1}^{\hat{T}} \sum_{w} w d_{e}^{*}(a, t, w)\right]=\left[\gamma \sum_{a} \sum_{t=1}^{T} \sum_{w} w d_{u}^{*}(a, t, w)+i_{S A} \sum_{a} \sum_{w} d_{u}^{*}(a, T+1, w)\right]
$$

Equation (3) equalizes the government revenue (equal to the taxable portion of the income of employed workers) with the expenditure of the government (equal to the measure of unemployed receiving unemployment benefits and social assistance income multiplied by the expenditure).

\subsection{Welfare, Inequality and Unemployment Duration Measures}

In order to rank each policy choice $\hat{T}$ given a budget balancing tax rate $\tau$, I use a standard consumption-based measure of overall welfare showing by how much the agents' consumption in each state should change such that the utilitarian welfare in the no entitlement for quitters scenario is equal to the utilitarian welfare associated with a given policy reform. Mathematically:

$$
\text { Welfare }=\left(\frac{\sum_{a, t, w, x} \lambda_{1}(a, t, w, x) v_{1}(a, t, w, x)}{\sum_{a, t, w, x} \lambda_{0}(a, t, w, x) v_{0}(a, t, w, x)}\right)^{\frac{1}{1-\mu}}
$$

where $\lambda_{i}$ is the steady state distribution of agents and $v_{i}$ is the associated value function for $i \in\{0,1\}$ with 0 standing for the status quo of no entitlement for quitters and 1 for a given policy reform. ${ }^{5}$

Furthermore, in order to measure (pre- and after-tax) income inequality associated

\footnotetext{
${ }^{5}$ Note that due to the functional form of the utility function in the separable search costs model, this metric is no longer valid. The adjusted one reads instead:

$$
\text { Welfare }=\left(\frac{\sum_{a, t, w, x} \lambda_{1}(a, t, w, x) v_{1}(a, t, w, x)+\sum_{a, t, w, x} \lambda_{0}(a, t, w, x) v_{0}^{S}(a, t, w, x)}{\sum_{a, t, w, x} \lambda_{0}(a, t, w, x) v_{0}^{C}(a, t, w, x)}\right)^{\frac{1}{1-\mu}}
$$

where $v_{0}^{S}(s)=-g(q(s)) \cdot 1_{x=u}+\beta \sum_{s^{\prime}} \Pi\left(s^{\prime} \mid s\right) v_{0}^{S}\left(s^{\prime}\right)$ (the search cost component of the value function before the reform), $v_{0}^{C}(s)=u(c(s))+\beta \sum_{s^{\prime}} \Pi\left(s^{\prime} \mid s\right) v_{0}^{S}\left(s^{\prime}\right)$ (the consumption component) and $c, q$ are the optimal decisions.
} 
with each policy, I use the Gini coefficient given by:

$$
\text { Inequality }=1-\frac{\sum_{i=1}^{n} \mathbb{P}\left(y_{i}\right)\left(S_{i-1}+S_{i}\right)}{S_{n}}
$$

where $y_{i}$ denotes (pre- or after-tax) income, $S_{i}=\Sigma_{j=1}^{i} \mathbb{P}\left(y_{j}\right) y_{j}, S_{0}=0$ and $y_{i}<y_{i+1}$. A coefficient of 0 means perfect equality.

Finally, I propose the following measure of expected mean unemployment duration:

$$
U D=\sum_{a} \sum_{t=1}^{T+1} \sum_{w}\left(t+\sum_{\hat{t}=t+1}^{\infty}\left(\hat{t} \prod_{\tilde{t}=t}^{\hat{t}-1} \mathbb{P}\left(w^{\prime}<\bar{w}(a, \min \{\tilde{t}, T+1\}, w)\right)\right)\right) d_{u}^{*}(a, t, w)
$$

i.e. the weighted (by mass of unemployed workers in given states) average of expected unemployment duration. Each worker's expected unemployment duration is given by the sum of products of possible unemployment periods $t$ and corresponding probabilities of moving into them.

\section{Calibration}

I calibrate the model to properties of the existing UI system in the US. The calibration of the non-separable model described below is later on referred to as the baseline calibration. I assume a monthly periodicity and the CRRA utility function $U(c)=\frac{c^{1-\theta}}{1-\theta}$ with a coefficient of risk aversion $\theta=3$. For exogenous separation probability, I choose a quarterly value of $\sigma=0.1$ from the Job Openings and Labor Turnover Survey as in Hall and Milgrom (2008). Moreover, since the model employed here abstracts from capital, I target the yearly interest of $2 \%$. This is a half of what is commonly assumed for calibration of macro models with capital (see e.g. McGrattan and Prescott (2005)).

The discount factor is assumed to be $\beta=0.918$. The value is chosen to match the evidence on savings of unemployed in Gruber (2001) and Chetty (2008) documenting that $17 \%$ of workers entering unemployment report zero gross financial wealth. However, upon excluding unsecured debt, i.e. looking at workers' net financial wealth, this number grows to $50 \%$ and moreover many workers below have negative positions. Since unemployment is often an unforeseen event, the second number may be also very relevant for the analysis. Therefore, I aim to replicate the observation of a number between $17 \%$ and $50 \%$ of newly unemployed workers with or close to zero savings. Importantly, note that although the value of $\beta$ may seem to be relatively low, it should not be seen 
as invalid because it is implied by the data. The saving grid consists of 60 equidistant points from $[0,1.1]$.

Table I: Wage offer distribution (pre-tax)

\begin{tabular}{ccccccccc}
\hline$w_{i}$ & 0.0297 & 0.0383 & 0.0493 & 0.0634 & 0.0815 & 0.1046 & 0.1343 & 0.1724 \\
\hline $\mathbb{P}\left(w_{i}\right)$ & 0.0022 & 0.0068 & 0.0182 & 0.0407 & 0.0758 & 0.1181 & 0.1541 & 0.1683 \\
\hline & & & & & & & & \\
& 0.2212 & 0.2840 & 0.3647 & 0.4686 & 0.6026 & 0.7758 & 1.0000 & \\
\cline { 2 - 7 } & 0.1541 & 0.1181 & 0.0758 & 0.0407 & 0.0182 & 0.0068 & 0.0022 & \\
\cline { 2 - 6 } & & & & & & &
\end{tabular}

As far as it concerns the wage offer distribution in the US, Hall and Mueller (2015) approximate it as log-normal, and more importantly they conclude that its standard deviation is 0.28 . However, once they also account for non-wage values, the dispersion goes up to 0.43. Thus, I pick an average of the two numbers and so I assume the wage offer distribution $\mathrm{F}$ to be log-normally distributed with dispersion parameter $\rho=0.35$ and $\mu=-1.7581$ (s.t. the support is on $[0,1]$ ). Also, I assume that there are $n=15$ different wages in the market. Noteworthy, if we think about some of workers in the economy as e.g. managers and waiters, the assumed variance parameter is very large. In real life such workers are facing different wage distributions with a much smaller dispersion. Nevertheless, the model accounts for this phenomenon to some extent by 1) the mechanism of reservation wages; and 2) the effective restrictions on possible search effort. The resulting wage offer distribution is presented in Table 1 and the implied equilibrium wage distribution is presented below in Figure 6. Importantly, the associated with the wage distribution "mean-min wage ratio" (as proposed by Hornstein et al. (2011)) amounts to 2.71 (i.e. $\frac{0.2840}{0.1046}$ ). This number falls between 2.54 (i.e. $\frac{\$ 38,428}{\$ 15,080}$ ) and 2.79 (i.e. $\frac{\$ 42,068}{\$ 15,080}$ ) which are the corresponding median-min wage ratios $^{6}$ in the US between 2009 and 2015 (computed using the CPS data and the minimum wage rate of USD 7.25 per hour as introduced in 2009).

Following the review of the UI system in the US by Pavoni and Violante (2007) and Moffit (2002), I take $\gamma=0.6, T=6$ and $i_{S A}=0.15 \cdot \bar{w}$. The first number translates into a replacement ratio of $60 \%$ of workers' last wage, the second number implies the UI entitlement for a maximum of half a year and then being followed by the social assistance income $i_{S A}$ set to $15 \%$ of the median wage in the steady state economy. To pin it down, I take first the average social assistance income in the year

\footnotetext{
${ }^{6}$ The bias stemming from using the mean-min wage ratio would be too big because of the very rich in the US.
} 
2000 comprising mostly of the Temporary Cash Assistance for Needy Families (TANF) and Food Stamps and amounting to approximately USD 879 for a family of three (as documented by Moffit (2002)). After accounting for the family size and the median ${ }^{7}$ personal income in the US in the year 2000 (as recorded in the CPS), we end up with the social assistance income amounting to $12.8 \%$ (i.e. $\frac{879}{3 \cdot 2300}$ ) of the median monthly wage income. I choose a number slightly higher in order to allow for some increasing returns to scale within a family. Finally, the baseline calibration to the US implies that quitters are entitled solely to the social assistance income and, in particular, not to the UI. However, in Section 4, I will look for an optimal value of the re-entitlement parameter $\hat{T}$.

For the search effort, I choose the grid to consist of $m=30$ equidistant points from the $[0,1]$ interval. More importantly, in the case of monetary search costs, parameters $(\alpha, \zeta)$ of the cost function $g$ are such that: (1) the baseline model under no-entitlement policy replicates the mean long-run US unemployment rate since 1930s equal to $7.10 \%$; and (2) the shape of a 'representative' worker's search effort along the unemployment path resembles the one documented by Krueger and Mueller (2010) for UI eligible (shown in Figure I.a). By 'representative', I mean here a 7-period average (weighted by steady states measures of workers in each saving and wage categories) behavior simulation of a newly unemployed worker following her optimal actions conditional on not having found employment. ${ }^{8}$

Note that in their work (and as is most common in the literature), the search effort is measured in job search minutes. Since effort in this paper is in monetary units and there is no empirical research on this subject, I aim to match the relative magnitudes of the search effort in different stages of unemployment for eligible workers. Thus, I look for parameters that give growth and decline rates of the model-imputed search effort for the 'representative' unemployed worker between the trough before the benefit exhaustion, the peak at the benefit exhaustion and the trough one month after the exhaustion which are approximately equal to the counterpart ratios in Krueger and Mueller (2010) for the weeks 14, 25/26 and 30. The parameters chosen for the search cost function are $\alpha=0.092$ and $\zeta=1.09$.

Another evidence on the job search behavior comes from Faberman and Kudlyak (2016). When combined with the one in Krueger and Mueller (2010), it suggests that the unemployed search behavior until the benefit exhaustion may in fact be U-shaped,

\footnotetext{
${ }^{7}$ The bias stemming from using the average would be too big because of the very rich in the US.

${ }^{8} \mathrm{I}$ use this construct, as opposed to using an average cross-sectional worker behavior, in order to control for composition effects in the latter.
} 
Figure I: Evidence on search effort

(a) Job search (in minutes) by unemployment duration (source: Krueger and Mueller (2010))

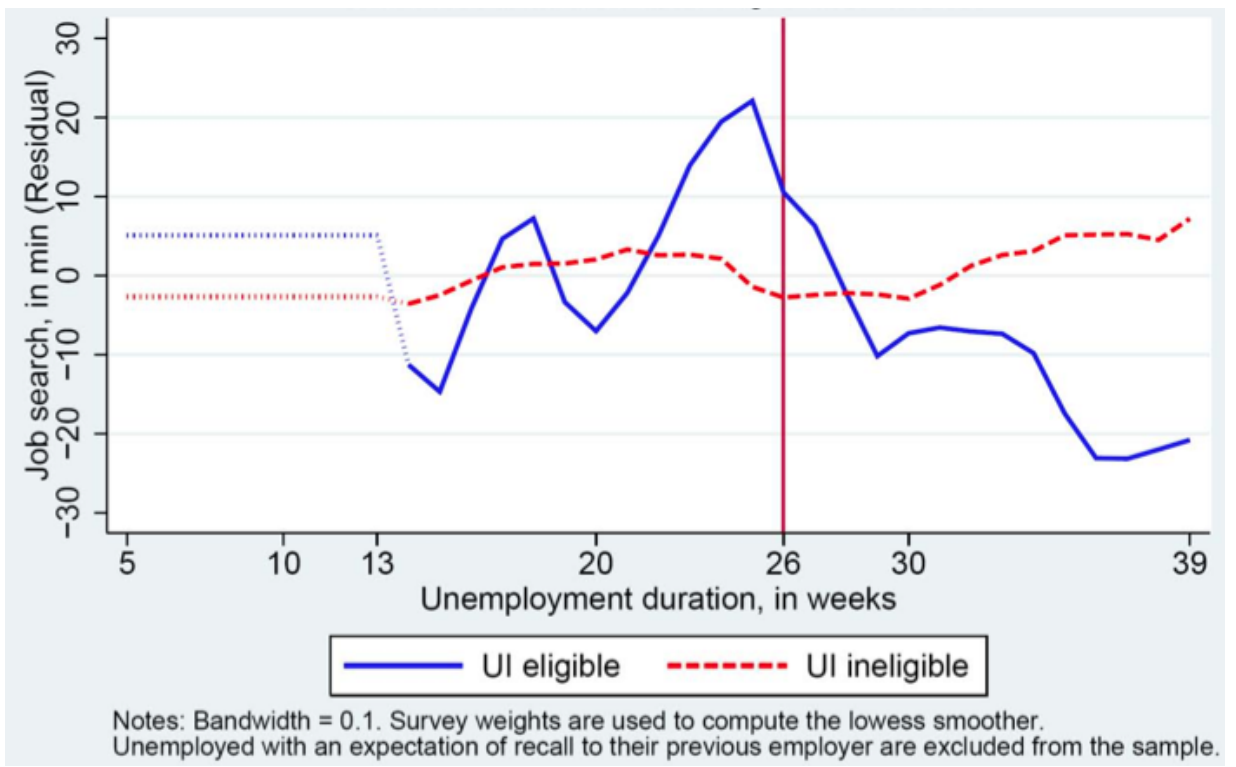

Note: To compute the ratios for calibration, one should add the regression mean of 32.1 to the residuals. Due to noisiness of the data in the first 14 weeks the Figure shows average time allocated to search, from week 14 on the Figure presents LOWESS-smoothed data based on residuals after removing searchers' individual characteristics such as age, sex, etc.

(b) Job search (number of applications sent) by unemployment duration (source: Faberman and Kudlyak (2016)) Note: Dashed lines represent $95 \%$ confidence intervals.

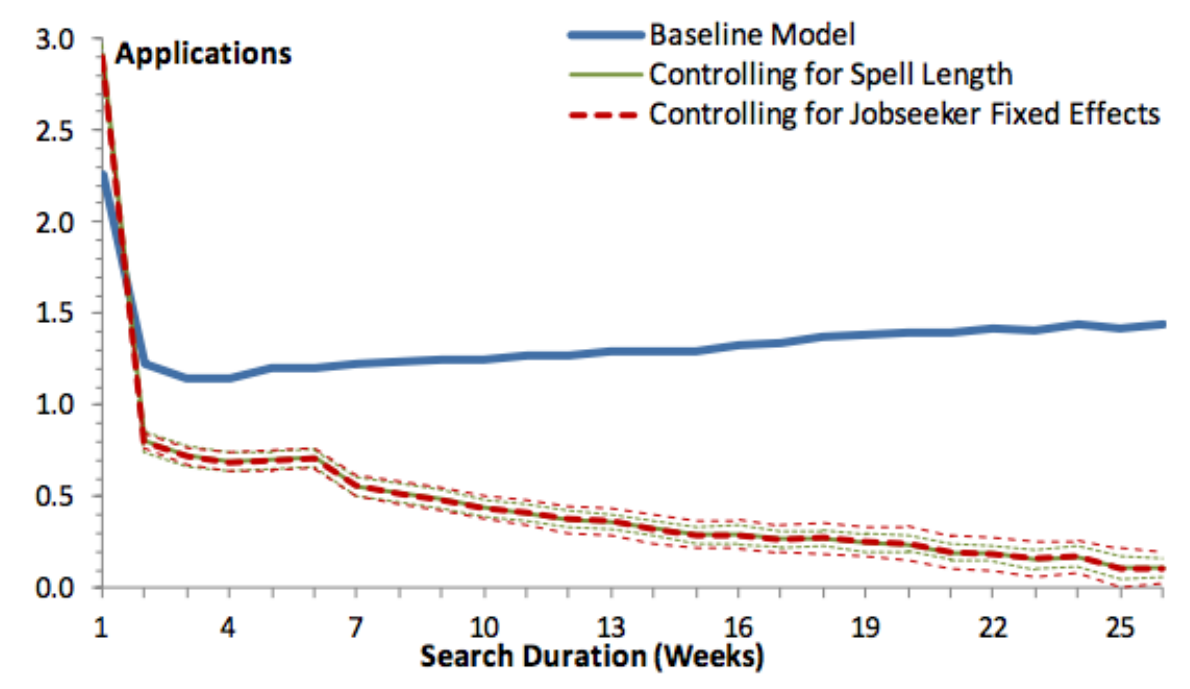


and followed by a decline after. In particular, they study relationship between search intensity and search duration using a micro data set containing information on a number of applications job seekers send to vacancies posted on an online job search website and corresponding unemployment spell lengths. Figure I.b presents their main findings: the number of applications sent initially declines steadily and then starts increasing slowly over time. However, once they control for fixed job seeker characteristics, the number of applications sent monotonically declines over time. At this point two comments are due. Firstly, their data come from the period of Great Recession when the UI benefits were extended to 99 weeks and so it is inapt to capture the spike at benefit exhaustion. Secondly, the fact that number of applications sent declines does not necessarily imply the same about the search effort. The latter is true as when workers apply for ever more jobs, the pool of (relevant) vacancies becomes ever smaller. Notwithstanding, the initial decline in search effort is still very plausible. This is especially likely given that the data for the first 3 months in Krueger and Mueller (2010) contains a lot of noise, and so authors report only average estimates.

Table II: Parameter values in the model

\begin{tabular}{cccc}
\hline parameter & interpretation & value $(\mathrm{NS} / \mathrm{S})$ & source/target \\
\hline \hline$\beta$ & discount factor & $0.918 / 0.94$ & target savings \\
\hline$r$ & interest rate & $0.1652 \%$ & $2 \%$ yearly interest rate \\
\hline$\sigma$ & risk aversion coefficient & 3 & modeling choice \\
\hline$\gamma$ & exogenous separations rate & $\frac{1}{10 \cdot 3}$ & JOLTS / Hall and Milgrom (2008) \\
\hline$T$ & replacement ratio for UI & 0.6 & UI in the US, Pavoni and Violante $(2007)$ \\
\hline$i_{S A}$ & periods of UI entitlement & 6 & UI in the US, Pavoni and Violante $(2007)$ \\
\hline$n$ & social assistance income & $0.15 \cdot \bar{w}$ & SA in the US, Moffit $(2002)$ \\
\hline$m$ & number of wages & 15 & modeling choice \\
\hline$a_{M}$ & search effort grid density parameter & 30 & modeling choice \\
\hline$\left(a_{\text {min }}, a_{\text {max }}\right)$ & savings grid density parameter & 60 & modeling choice \\
\hline $\mathrm{F}$ & savings grid bounds & $(0,1.1)$ & modeling choice \\
\hline$\mu$ & distribution of wage offers & log-normal & Hall and Mueller $(2015)$ \\
\hline$\varrho$ & dist. log-scale parameter & -1.7581 & support of F on [0,1] \\
\hline$\alpha$ & dist. shape parameter & 0.35 & Hall and Mueller $(2015)$ \\
\hline$\zeta$ & search cost f-n $g$ parameter 1 & $0.092 / 15.22$ & target U and search profile \\
\hline
\end{tabular}

Notation: NS - non-separable utility, S - separable utility.

However, I do not use the evidence from Faberman and Kudlyak (2016) directly for calibration since (1) it is difficult to combine this search effort measure with the 
Table III: Empirical and implied moments

\begin{tabular}{ccccc}
\hline Moment & $q$ growth rate & $q$ decline rate & U Rate & $\%$ U liq. constr. \\
\hline \hline Empirical & $\frac{54.1}{19.1} \approx 2.83$ & $\frac{54.1}{22.1} \approx 2.44$ & $7.10 \%$ & $17 \% / 50 \%$ \\
\hline Non-Separable Model & 1.56 & 2.53 & $7.19 \%$ & $23 \% / 50 \%$ \\
\hline Separable Model & 1.26 & 1.00 & $9.29 \%$ & $42 \% / 79 \%$ \\
\hline
\end{tabular}

Note: Table presents approximate moments of the worker search effort documented in Krueger and Mueller (2010), of the US long-term mean unemployment rate and of the percentage of newly unemployed workers who are (close to) liquidity constrained documented in Gruber (2001) and Chetty (2008) and the corresponding implied moments in both versions of the model.

Notation: U Rate - Unemployment Rate; \% U liq. constr. - share of liquidity constrained among all newly unemployed workers.

other one in Krueger and Mueller (2010); and (2) for the purpose of this paper the search effort around the benefit exhaustion is much more relevant. Nevertheless, I show in Section 4 that the model with monetary search costs and savings generates the discussed U-shape behavior.

On the other hand, for the model with separable search costs, I pick different values for parameters. This is due to the fact that workers are no more facing search effort constraints and so behave differently. Consequently, I assume $\beta=0.94$ and the search costs to be much higher by choosing $\alpha=15.22$ and $\zeta=2.65$. Table II summarizes the calibration.

Finally, Table III presents the targeted empirical moments and the ones implied by the two models tested. The model with monetary search costs matches the empirical moments pretty well. In particular, although in the steady state there are close to nil newly unemployed workers without any savings, there is $23 \%$ and $50 \%$ of population with savings below 0.09 and 0.19 , respectively. The latter two numbers translate into only $32 \%$ and $67 \%$ of the steady state mean monthly gross wage income. The only moment somewhat off the target is the growth rate of search effort from the trough when still on UI till the benefit exhaustion.

On the other hand, the separable model performs relatively poorly. Firstly, it is not able to match the target of $7.10 \%$ unemployment rate. ${ }^{9}$ Secondly, $42.83 \%$ of newly

\footnotetext{
${ }^{9} \mathrm{I}$ have also tried to calibrate the separable search costs model with a richer mapping of the worker's effort to the effective transition probability given by $f(q)=\xi(1-\exp (-\chi q))$. Nevertheless, the model's unemployment rate has not gone down significantly in spite of the two additional free param-
} 
unemployed are with zero savings. While the latter number is close to the upper bound evidence, having $79 \%$ of newly unemployed with savings below 0.09 (and $82 \%$ below 0.19 ) is significantly off the empirical evidence. The reason for the latter is a low $\beta$ which effectively governs not only the saving moment, but also the unemployment rate: the more impatient are the workers, the less picky they are about the job offers. In other words, the chosen value of $\beta$ constitutes a compromise between missing the unemployment rate target and overshooting the savings target. Finally, the worker search behavior does not match the empirical evidence: although the search effort does grow over the unemployment spell, it remains at a constant level after the benefit exhaustion (in line with previous findings in the literature). Section 4.1.2 provides a more detailed discussion of unemployed worker behavior shedding some more light on why the second model fails.

\section{Results}

In this section I discuss the results from solving the calibrated model for different reentitlement policy experiments. In Section 4.1, I discuss the worker behavior. Section 4.2 presents the equilibrium properties of the economy under different policy settings. In particular, I discuss the potential welfare gains associated with following the entitlement policy. Section 4.3 discusses the feature of omitted on the job search. Finally, Section 4.4 discusses some of differing features between the European and US labor markets in light of the results discussed here.

Importantly, many of the main conclusions in the separable search cost model are qualitatively the same. If this is not the case, I discuss these differences in the due place. Appendix B contains all the twin figures for the separable search costs model.

Additionally, as a robustness check, Appendix C contains quasi comparative statics results, i.e. a comparison of the model predictions when one of parameters changes. For description of the numerical method used for solving the model see Appendix D.

\subsection{Worker Behavior}

Figures II and III present the representative unemployed and cross-sectional employed (respectively) worker behavior in the model with monetary search costs and both no entitlement for quitters $(N E)$ and with UI entitlement after 1 month on the job $(\hat{T}=$ eters. 
1). In particular, they show 1) workers' search behavior, current saving positions, reservation wage and consumption levels; and 2) quit or stay on the job decisions. The first part of this Section focuses only on the baseline policy of NE. The differences between the two policies are discussed in Section 4.1.2. At the end, in Section 4.1.3, I discuss some testable implications of the model.

\subsubsection{Worker Behavior Under No Entitlement for Quitters}

Figure II with search effort behavior shows that the baseline model replicates very well not only the empirical evidence of the spike at benefit exhaustion but also generates a plausible U-shaped path (as discussed in Section 3) of the search effort. ${ }^{10}$ In particular, as workers enter the first period of unemployment they have quite some savings, and so the income effect dominates: for a given probability of finding a good job, the cost in terms of marginal utilities is relatively low, and so workers want to invest a lot of their resources into finding a good job. However, as workers deplete their savings, the substitution effect starts dominating: exercising extra search effort by agents becomes more expensive in terms of marginal utility. Therefore, we get the decreasing effort in the first 3 months.

Note that between the months 3 and 5 there is a little spike in search effort. The increase in effort comes about because of workers getting closer to the benefit exhaustion. Then, the decrease is a consequence of increased savings in the month 5 (note the increase in saving position in the month 6) as a precautionary measure against falling into the social assistance.

The spike at the benefit exhaustion in the last month of benefit entitlement is a consequence of workers trying hard to avoid falling into the social assistance state which may imply kind of a long term unemployment lock-in and so having to agree on a much worse job offer than before the exhaustion. The latter is also reflected by the steady decrease in the reservation wage (behavior akin to discouragement). In other words, as workers approach the period of benefit exhaustion the income effect dominates (the return in form of finding a job jointly with avoiding the social assistance state in the next period is very high). After the benefit exhaustion, search effort drops significantly as workers' disposable income gets much smaller.

Finally, plots in Figure II speak in favor of dynamics generated by the model. Firstly, the decline of reservation wage over the spell of unemployment is in line with empirical

\footnotetext{
${ }^{10}$ Thus, if the "U-shape conjecture" is true, then the monetary search costs model rationalizes the worker search behavior.
} 
evidence documented in Krueger and Mueller (2014). Secondly, the wealth holdings decline steadily along the unemployment spell - as documented in Gruber (2001). Thirdly, the increase in search effort and decrease in reservation wage imply together an empirically documented spike in unemployment exit rate. However, there is still an ongoing debate in the literature whether this spike is due to a spike in the re-employment probability or rather only due to workers moving out of the labor force (see e.g. discussion in Card, Chetty and Weber (2007)).

On the other hand, the worker behavior in separable search costs model fails to match the empirical evidence (see Figure VIII). The search effort neither drops at the benefit exhaustion nor is U-shaped. Furthermore, the implied savings behavior is also counterfactual as savings decline over the first 4 months and then increase steadily. These dynamics are due to the fact that in this model search costs do not enter the budget constraint and so workers face no trade-off between exercising search effort and accumulating savings against the social assistance state.

Figure II: Representative unemployed worker behavior with monetary search costs
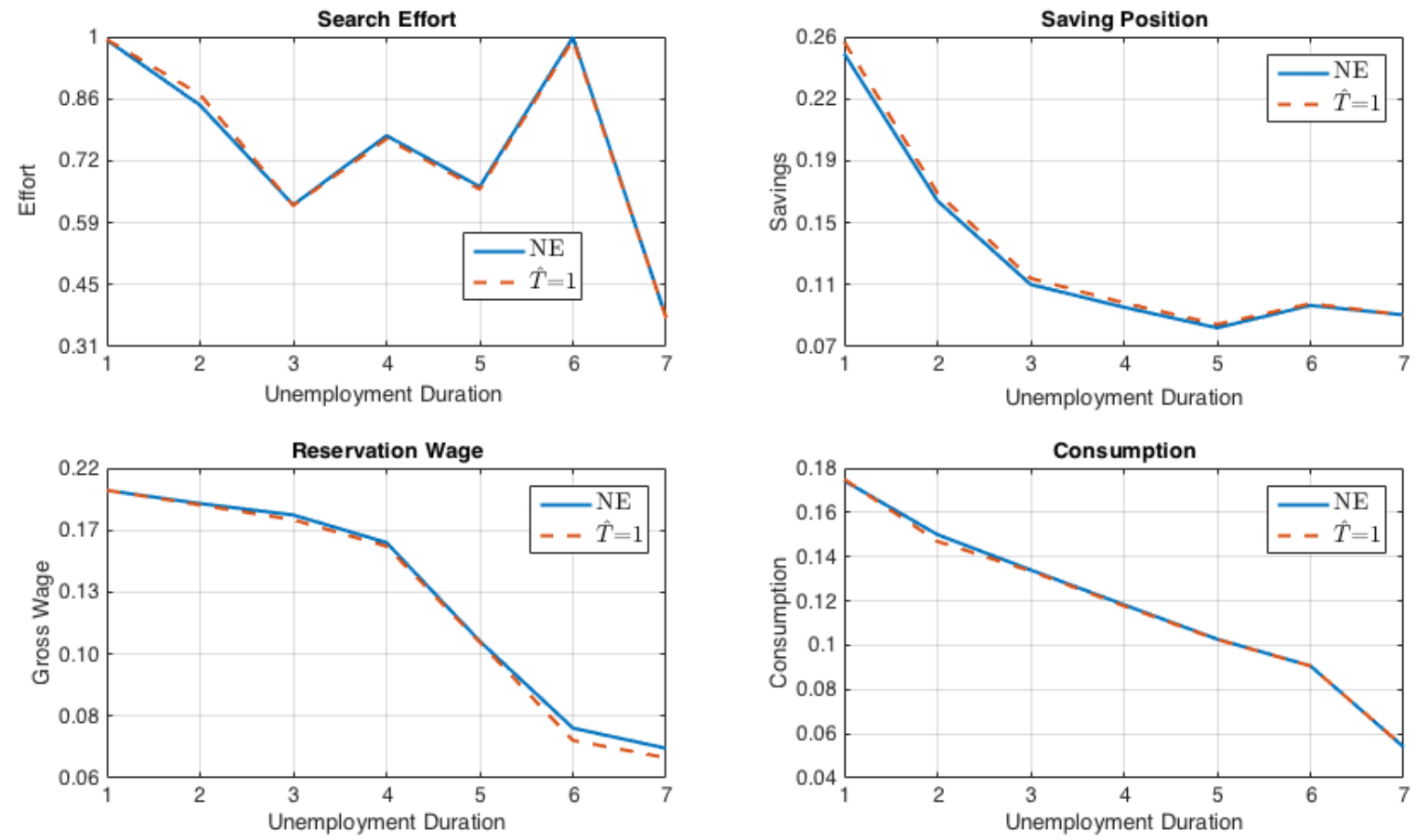

Notation: NE - no-entitlement, $\hat{T}=1$ - re-entitlement after 1 period on the job.

Furthermore, Figure III presents behavior of employed workers with minimum and maximum savings across all the 15 wage categories. In the model with no entitlement 
for quitters, the workers with minimum savings quit all the jobs with $w \leq 0.05$. On the other hand, the workers with maximum savings are much more picky and quit all the jobs with $w<0.22$. This means that the model with no entitlement for quitters is (realistically) characterized by a positive mass of people leaving jobs: workers with little or no savings find it optimal to enter some jobs for a number of periods in order to build up their saving accounts and then go back to unemployment and use savings in order to find a better match. In fact, in the steady state of the model with no entitlement, the quit rate ${ }^{11}$ amounts to $0.68 \%$. For comparison, the quit rate in the separable search costs model amounts to only $0.1 \%$.

Figure III: Employed worker behavior with the monetary search costs
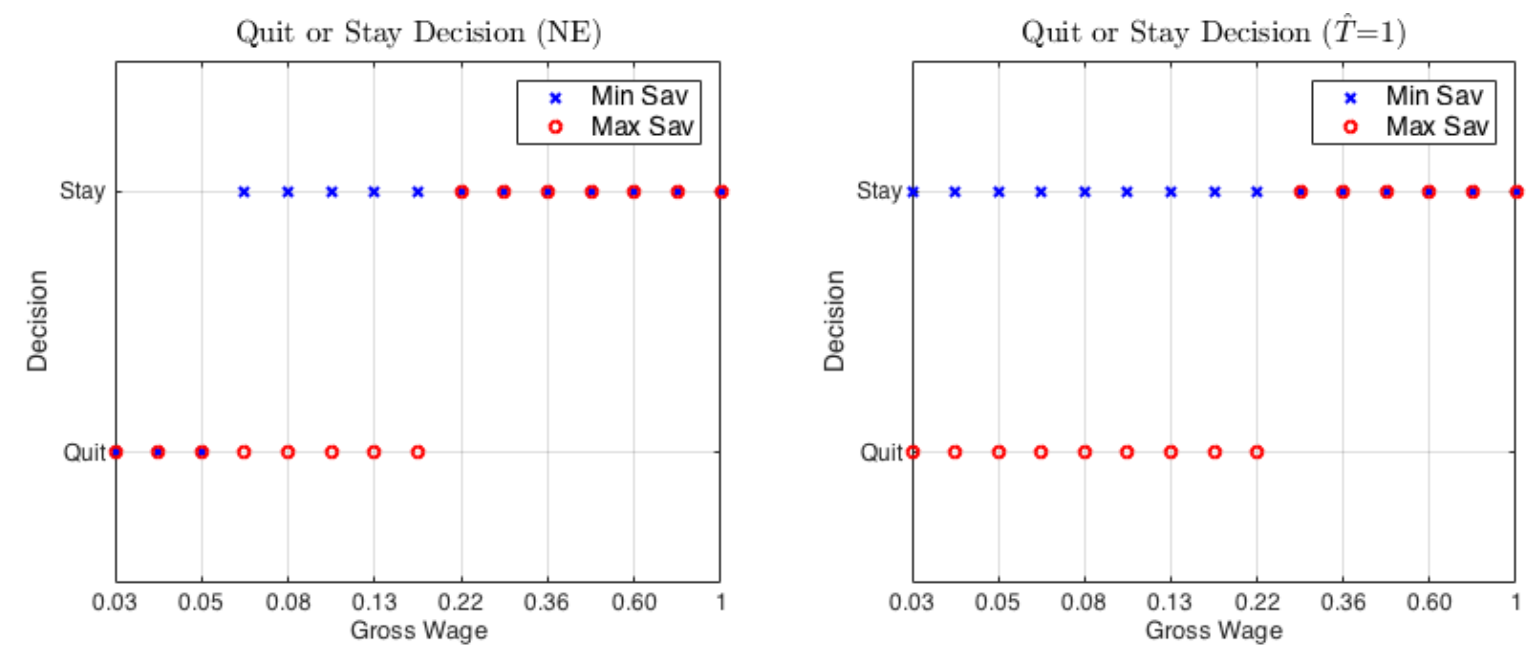

Notation: 1 stands for staying on the job, 0 for quitting; Min (Max) Sav - behavior of a worker with minimum (maximum) savings conditional on her current wage; NE - no-entitlement, $\hat{T}=1$ - re-entitlement after 1 period on the job.

According to the JOLTS and CPS data for the years ${ }^{12} 2000-2015$, the average quit rate in the US amounted to $1.84 \%$. However, since some quits reflect job-to-job transitions, this number constitutes an upper bound for comparison with the model-generated quit rate. In particular, between the years 1980-2015, quitters constituted on average $10.72 \%$ of the unemployed ${ }^{13}$. Thus, the 'adjusted' quit rate for this period amounts to $0.73 \%$ (i.e. $10.72 \% \cdot \frac{6.42 \%}{93.58 \%}$ ).

Summing up, even tough under the baseline policy quitters are not entitled to UI, some workers still decide to leave their jobs in order to find a better one and this

\footnotetext{
${ }^{11}$ Quit rate is defined as the number of quits during the month as a percent of total employment.

${ }^{12}$ The relatively short period taken is due to data availability.

${ }^{13}$ This number does not include unemployed workers from temporary jobs or on temporary lay-offs.
} 
is especially true at the lower end of wage distribution. Moreover, the data and the model-dynamics give strong support to the mechanism presented in this paper.

\subsubsection{Worker Behavior Under Entitlement for Quitters}

I begin with discussion of the employed worker behavior and then move to the case of unemployed ones.

The right panel in Figure III shows that workers with minimum savings stay now in all types of jobs. Note that this is obviously not to say that they keep working until exogenously separated. Similarly as before, they stay on these jobs for some periods in order to accumulate savings and then quit in order to find a better job and collect their UI. I refer to this kind of worker behavior as being opportunistic since now workers use some lower paid jobs not only to accumulate savings but also to receive the welfare payments. Consequently, under the new policy the quit rate goes up to $1.59 \%$ from $0.68 \%$.

Furthermore, the model with separable search costs generates quite different conclusions about the employed worker behavior (see Figure IX). In particular, upon the policy reform, both workers with minimum and maximum savings stay in fewer jobs than before the reform. As search costs are non-monetary, workers do not spend as much time in their jobs in order to accumulate savings and so quit those just after the re-entitlement. The quit rate goes up now to $1.91 \%$ from $0.1 \%$.

On the other hand, the representative unemployed worker behavior in the case of $\hat{T}=1$ is affected mostly on the reservation wage margin before the benefit exhaustion (see Figure II). This means that the new policy extracts some workers from the social assistance by making the low paying jobs more attractive due to the additional reentitlement value. Nevertheless, the overall small impact should not be surprising given that the policy is aimed at the employed workers who would like to quit and so affects directly the value of being employed, and only indirectly the value of being unemployed.

However, since the discussion above was about a representative worker, there may still be some categories of workers who are affected more significantly. To this extent, Figure IV presents the representative worker behavior conditional ${ }^{14}$ on recent wage $w=0.17$ and assets $a \in[0.35,1.1]$. Post-reform workers enter unemployment wealthier and so are able to search and consume more. The higher stock of savings comes from a better employment history of an average worker - see the discussion in Section 4.2. Finally, notice the interesting crossing of reservation wage functions. In the first 4

\footnotetext{
${ }^{14}$ See Section 4.2 below for explanation on how this group has been identified.
} 
months of unemployment the post-reform workers are more picky as they have quit their jobs exactly in order to find a better one. However, once the unemployment spell gets longer, the post-reform workers want to avoid the long-term unemployment and so are willing to take up some less paying jobs.

Finally, in the model with separable search costs, the reform affects the representative worker by much more ${ }^{15}$ (see Figure VIII). Since the value of the (easy to find) low paying jobs in the post-reform economy is increased (which translates into the gap between the values of being unemployed and employed becoming smaller), the workers do not find it optimal to search as hard as before and so the search profile is shifted down.

Finally, note that the introduction of entitlement for quitters is a form of increasing the overall UI generosity. Thus, the results on search behavior suggest that an increase in the UI generosity need not necessarily lead to a decrease in search effort (as was usually found in the literature). I further expand on this point in Appendix C.

Figure IV: Representative unemployed worker behavior with $w=0.17, a \in[0.35,1.1]$ and monetary search costs
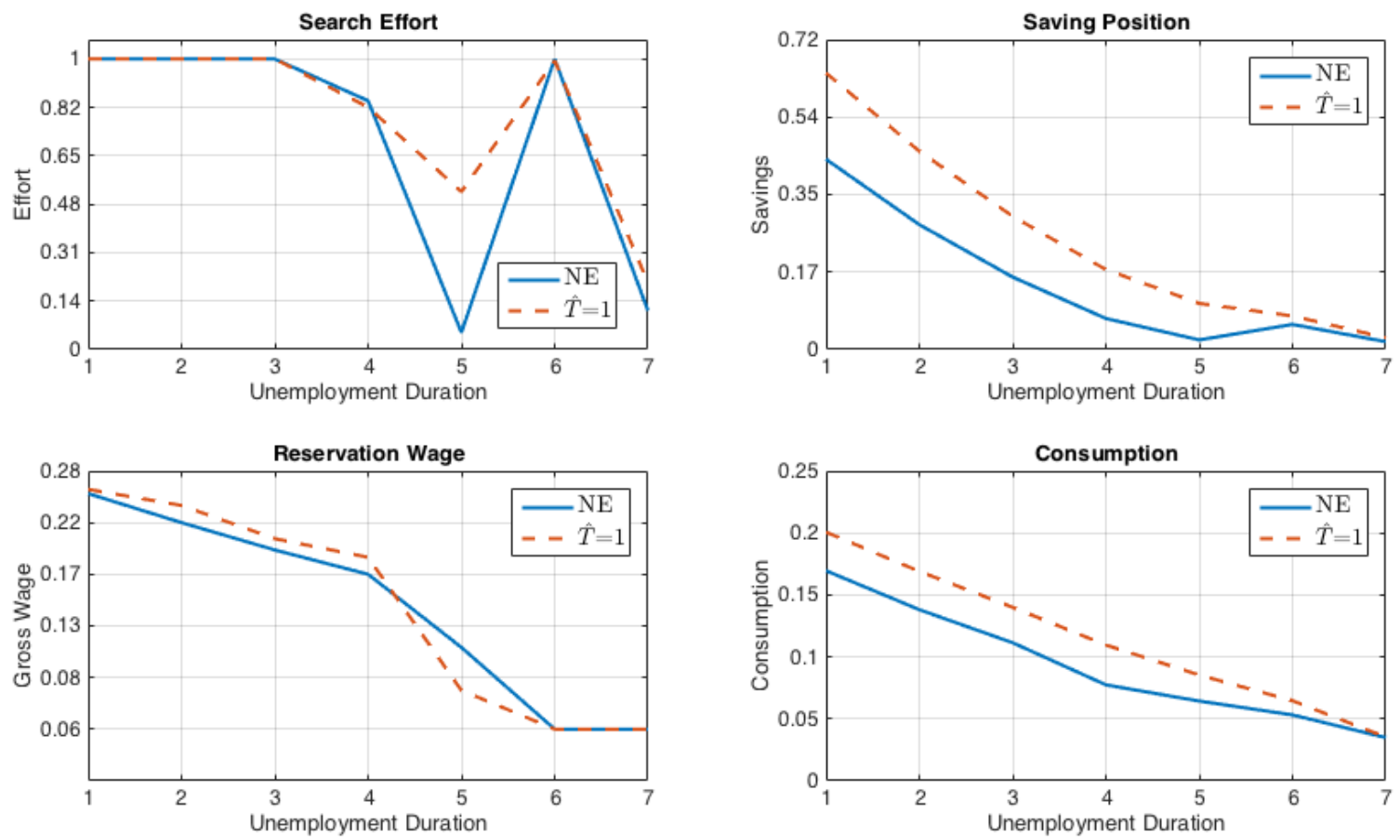

Notation: NE - no-entitlement, $\hat{T}=1$ - re-entitlement after 1 period on the job.

\footnotetext{
${ }^{15}$ For this reason I do not plot the twin of Figure 4 for the separable search costs model.
} 


\subsubsection{Worker Behavior and Financial Wealth}

Notice, however, that the above dynamics of unemployed workers were weighted averaged across the wage and saving positions. To this end, Figure $\mathrm{V}$ presents search and reservation wage behavior of poor (with 0 savings) and wealthy (with maximum savings) worker with the recent wage $w=0.28$ in the pre-reform economy. It can be immediately seen that the worker with less savings 1) is effectively searching much less; and 2) is less picky about the job offers. Since workers in the model are ex-ante identical, these observations deliver important implications that can be tested empirically. Are similar people differing only with respect to their financial wealth searching with different intensity? Do they differ with respect to their reservation wages? And so finally: are they more likely to end up in better paying jobs?

Figure V: Behavior of poor and wealthy unemployed workers with monetary search costs and no entitlement
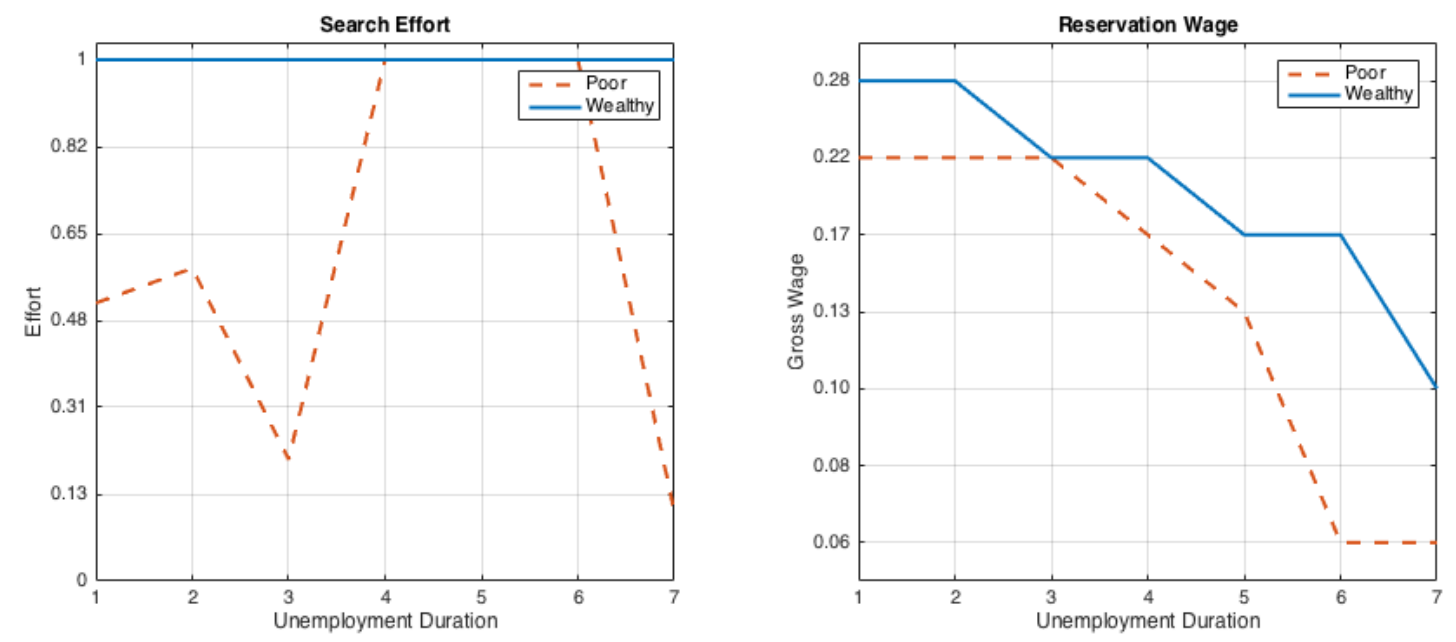

Notation: Poor - unemployed worker with $w=0.28$ and $a=0$; Wealthy - unemployed worker with $w=0.28$ and $a=1.1$.

Although the separable model delivers qualitatively the same dynamics of the reservation wage, it differs with respect to the search behavior (see Figure X). Now, since workers can adjust their search effort arbitrarily, the poor worker consumes less and so has more incentives to search harder in order to get back to employment.

\subsection{Employment, Welfare and Inequality}

In this section, I discuss first the distributional implications of the policy reform. Then, I move on to analyzing key equilibrium statistics of the pre- and post-reform economies 
like the associated welfare, unemployment and inequality rates. ${ }^{16}$ In particular, I show that following the policy of entitlement for quitters is associated with significant welfare gains and reduction in income inequality.

Figure VI: Distribution of workers' savings and income with monetary search costs
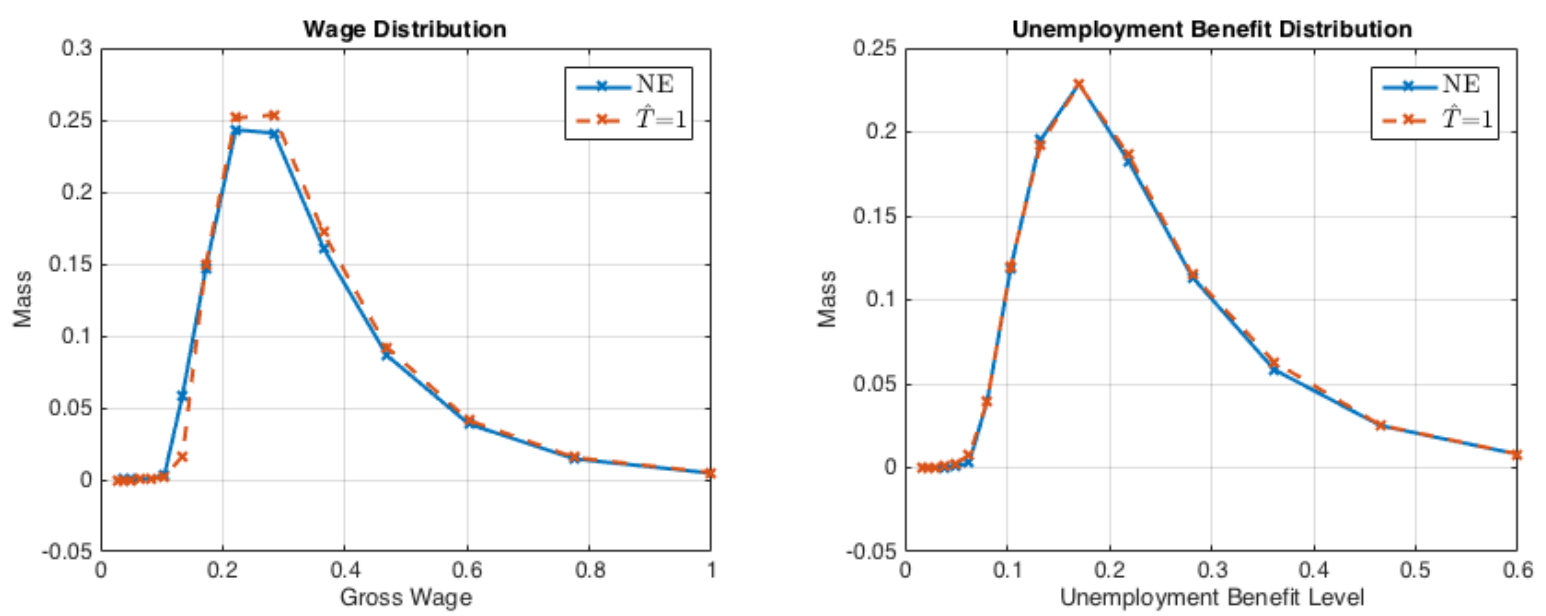

Notation: NE - no-entitlement; $\hat{T}=1$ - re-entitlement after 1 period on the job; Mass - a share of workers in a given category out of all employed or unemployed, respectively.

First of all, Figure VI presents the steady state distributions of workers' income in the two economies with $N E$ and $\hat{T}=1$. The first plot with wages shows that the reform allows workers to improve upon the average quality of their match. In particular, before the reform there were $5.88 \%$ of workers in jobs paying less than $w=0.13$ and only $1.79 \%$ post-reform. Note that the changes in distribution of unemployment benefits do not follow the ones in wage distribution very closely. This is because under the entitlement policy $\hat{T}=1$ there are more voluntary quits in the lower wage categories, bringing the benefit distributions for $N E$ and $\hat{T}=1$ close to each other for wages below 0.2 .

Consequently, as the above discussions suggest, the new policy affects mostly workers at the lower end of the wage distribution. Since these workers have a relatively high marginal utility from consumption, the welfare impact of the policy reform on this group can be potentially very large. This is confirmed in Figure VII which presents the breakdown of welfare gains (measured with the metric (4)) associated with the new policy for six wage categories in which there are at least $3 \%$ of employed (these plots cover $90 \%$ of employed in the economy with no entitlement). In particular, we observe that the highest welfare gains equivalent to between $6 \%$ and $10 \%$ of life-time

\footnotetext{
${ }^{16}$ Based on the computer results for the employed parameter values, the equilibria presented here are the unique ones.
} 
consumption are for the employed workers (employment state E) with $w \in\{0.13,0.17\}$ and some positive savings. These gains reflect the insurance value of the policy reform: as the associated risk with being unemployed becomes lower, workers in low wage categories are now more likely to quit in order to search for a better match.

Figure VII: Breakdown of welfare gains with monetary search costs
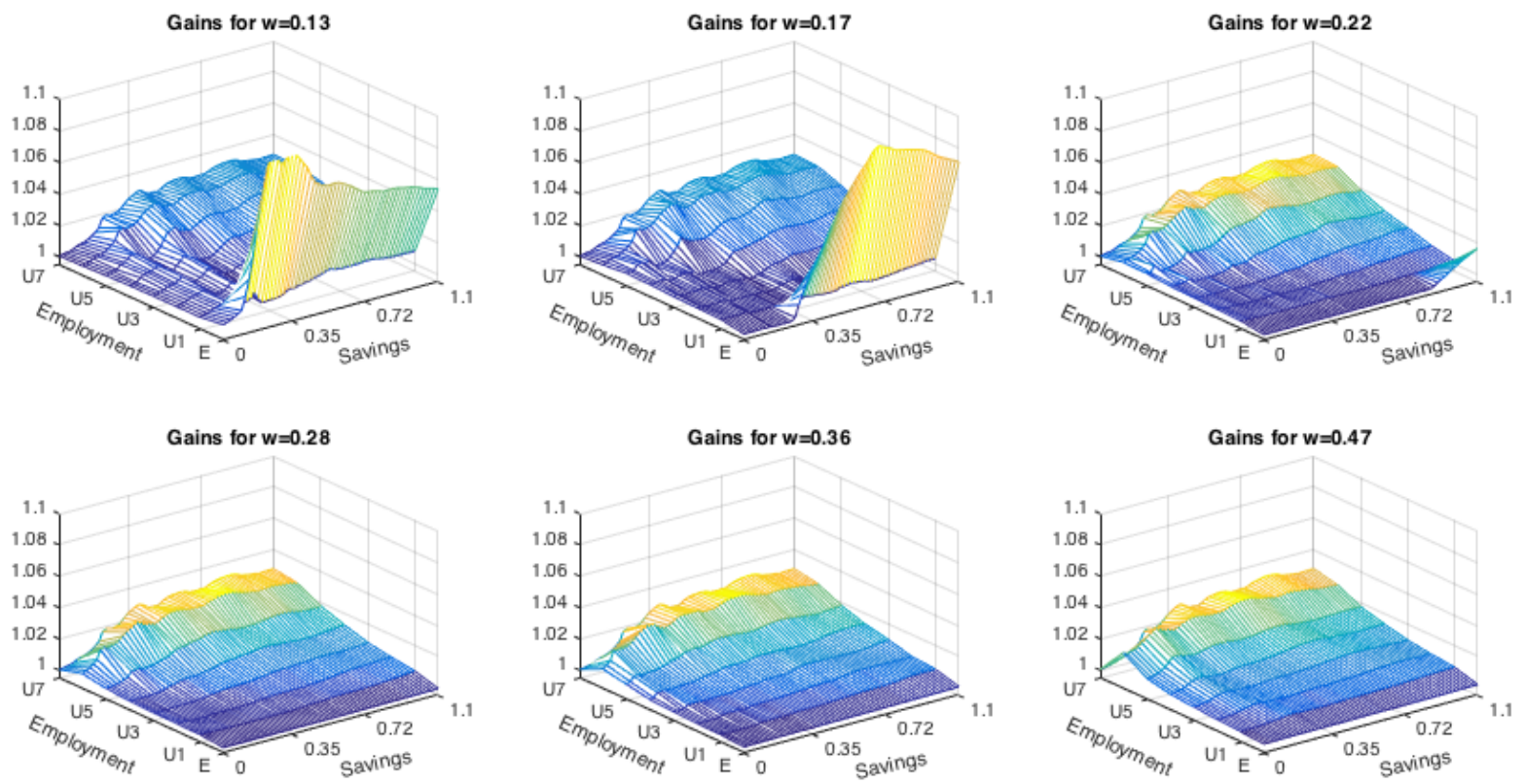

Notation: Employment state E stands for being currently employed; employment states U1 U7 stand for being either on UI (between 1 and 6) or on social assistance (state 7).

On the other hand, there are also significant welfare gains for unemployed workers in all the wage categories depicted. These gains are especially high at between $2.5 \%$ and $3 \%$ around the state of social assistance (state U7). This reflects the additional non-wage value of low-paid jobs which workers are now more likely to accept in the post-reform economy (recall the worker behavior discussed above). Moreover, note that: 1) employed workers with higher wages do not gain much as they are would not want to quit anyway; and 2) virtually no one is loosing from the reform (discussion below explains why).

All the welfare conclusions in case of the model with separable search costs are similar (see Figure XII). The only difference is that the welfare gains are spread more uniformly. This is due to the fact that the optimal post-reform search effort is shifted 
down (for reasons discussed above), which consequently reduces the search costs of all the unemployed workers.

Table IV summarizes key statistics of the equilibrium unemployment rate, budget balancing tax rate, welfare, income inequality and unemployment duration for both models with non-separable and separable utility functions. First of all, notice that following the policy of entitlement for quitters is associated with a higher unemployment rate and so with a higher budget balancing tax rate. Nevertheless, in both cases of non-separable and separable search effort cost assumptions there is an (overall) welfare improvement associated with following the entitlement policy $(\hat{T} \in\{1,2,3,6\})$ as compared to the actual US policy of no entitlement $(N E)$. In particular, the policy of entitlement for quitters after having worked for at least 1 month $(\hat{T}=1)$ results in the highest long-run welfare gains equivalent to a $4.38 \%$ and $3.69 \%$ increase in the life-time consumption, for non-separable and separable models respectively. Consequently, the benefits of providing search subsidy to workers (in form of insurance for employed and extraction of long term unemployed into employment) outweigh the costs generated by the moral hazard of rejecting or quitting jobs (in form of a higher tax rate needed to finance UI spending given higher unemployment rate).

Table IV: Main results of the model

\begin{tabular}{|c|c|c|c|c|c|c|c|c|c|c|c|c|}
\hline \multirow{3}{*}{$\hat{T}$} & \multicolumn{2}{|c|}{$\tau(\%)$} & \multicolumn{2}{|c|}{ U Rate $(\%)$} & \multicolumn{2}{|c|}{ C.E. Welfare (\%) } & \multicolumn{4}{|c|}{ Income Inequality (\%) } & \multicolumn{2}{|c|}{ UD (months) } \\
\hline & \multirow{2}{*}{ NS } & \multirow{2}{*}{ S } & \multirow{2}{*}{ NS } & \multirow{2}{*}{$\mathrm{S}$} & \multirow{2}{*}{ NS } & \multirow{2}{*}{$\mathrm{S}$} & \multicolumn{2}{|c|}{ NS } & \multicolumn{2}{|c|}{$\mathrm{S}$} & \multirow{2}{*}{ NS } & \multirow{2}{*}{$\mathrm{S}$} \\
\hline & & & & & & & pre-tax & after-tax & pre-tax & after-tax & & \\
\hline 1 & 5.84 & 8.07 & 7.57 & 11.18 & 104.38 & 103.69 & 22.82 & 22.69 & 20.63 & 20.33 & 4.03 & 6.44 \\
\hline 2 & 5.81 & 8.01 & 7.55 & 11.01 & 104.35 & 103.02 & 22.81 & 22.69 & 20.66 & 20.36 & 4.05 & 6.40 \\
\hline 3 & 5.79 & 7.96 & 7.54 & 10.92 & 104.31 & 102.84 & 22.82 & 22.70 & 20.68 & 20.39 & 4.06 & 6.38 \\
\hline 6 & 5.74 & 7.85 & 7.50 & 10.70 & 104.26 & 102.65 & 22.83 & 22.70 & 20.71 & 20.44 & 4.08 & 6.35 \\
\hline$N E$ & 5.65 & 7.41 & 7.19 & 9.29 & 100 & 100 & 23.72 & 23.61 & 20.68 & 20.48 & 4.21 & 6.18 \\
\hline
\end{tabular}

Notation: C.E. Welfare - life-time consumption-equivalent welfare increase; U Rate - Unemployment Rate; UD - unemployment duration, NS - results for a model with non-separable utility assumption, $\mathrm{S}$ - with separable utility, $\hat{T}$ - required number of months on the job in order to get eligibility for benefits after quitting, $N E$ - no entitlement for quitters policy.

To understand the underlying trade-off better, note first that the required increase of 0.19 p.p in the budget balancing tax rate is of a very small magnitude. Thus, as the currently employed workers barely notice the change in the tax rate, there is virtually no one loosing from the policy reform and (as discussed above) there are significant gains for the workers in low wage categories and for the long-term unemployed. ${ }^{17}$ This

\footnotetext{
${ }^{17}$ Moreover, the policy reform also serves as an indirect insurance for workers in high wage categories leading to some gains off-setting the negative impact of the tax increase. This is true as every worker in
} 
small increase in the tax rate is due to two factors: 1) a relatively small increase in the unemployment rate due to a relatively small increase in the quit rate (change from $0.68 \%$ to $1.59 \%$ ); and 2) an improvement of average match quality leading to a higher average tax revenue per worker.

Interestingly, under both assumptions of separability and non-separability the model kills two birds with one stone: the re-entitlement policy leads not only to an increase in efficiency but also in (both pre- and after-tax) equity. First of all, although unemployment rate goes up, the mass of long-term unemployed with social assistance income declines sixfold. Secondly, due to the higher tax rate, the after-tax income of employed individuals gets closer to the income of unemployed.

Similarly, the optimal policy is characterized by $\hat{T}=1$, as opposed to $\hat{T}>1$, exactly due to the effects on long-term unemployment. As the parameter goes up, the non-wage value of low-paid jobs is reduced and so the reservation wage of workers unemployed for 5-7 periods increases (see Figure II with reservation wage and note that $N E$ corresponds to $\hat{T}=\infty$ ). Consequently, there are more workers ending up poor (with high losses in marginal utility terms) in long-term unemployment which they cannot escape easily.

Moreover, as the long-term unemployed workers in the post-reform economy become less picky about wage offers, the unemployment duration goes down. Notice that this is not true in the separable search costs model: although also here the reservation wage is lower under the policy $\hat{T}=1$ as compared to $N E$, the level of the post-reform search effort is shifted down (as explained above in Section 4.1.2) leading to opposite conclusions.

Notice that the model delivers realistic dynamics in terms of other untargeted moments, again speaking in favor of the robustness of results. First of all, the implied unemployment duration of 4.2 months is just in line with the average mean unemployment duration in the FRED dataset for the years 1980-2015.

Secondly, the implied budget balancing tax rate of $5.65 \%$ is not too unrealistic. Although the average unemployment tax rate in the United States varies (depending on the state) from $0.05 \%$ to $2 \%$, as reported by Henchman (2011), these tax rates are in many cases too low as during many recessions some of the unemployment insurance trust funds became insolvent due to too low fund reserves and increased unemployment caused by economic downturn.

Finally, the model generates substantial income inequality. Nevertheless, due to the

the economy faces a positive probability of becoming unemployed and being unlucky in receiving low wage offers. In such a case, a worker with previously high wage may end up in long-term unemployment where she would benefit from the reform. 
simplifying assumption of worker ex-ante homogeneity, the implied after-tax income inequality of $23.61 \%$ is 14 p.p. below the corresponding Gini index for the US (according to the OECD).

\subsection{On The Job Search}

The model (and so the results above) abstracted from an empirically important feature of the on the job search. Fallick and Fleischman (2004) constructed a dataset based on the CPS from February and March 1997 and 1999 and report that out of all the employed people around $4.4 \%$ engaged in active on the job search. After two months, out of those actively searching around $11.3 \%$ reported having a new employer and around $5.6 \%$ reported being unemployed.

Moreover, up to $80 \%$ of job to job changers in their sample were not actively searching on the job. Such transitions may be due to various reasons such as 1) some of the workers having a very short (and so unrecorded in the data) period of unemployment in-between, 2) due to poaching, or 3) due to having found a job through their networks. The first case is covered by the mechanism employed in this paper. Nonetheless, a waitress working in a restaurant may be very likely poached by another restaurant or get information about a position in a friend's restaurant with a slightly higher wage. Obviously, my model is not suited for the analysis of such phenomena. However, given the discrete nature of the wage grid employed in this paper, one can think about each wage as representing some particular job category. With this interpretation in mind, it seems plausible to think that a waitress may be better-off leaving her job and her current network in order to focus her search effort on finding a new job (ideally a much better paid one) as her current network may be unlikely to provide her with such an opportunity.

Nevertheless, it is easy to see that a standard on the job search extension of the model would preserve qualitative nature of the results if the difference between the costs of on- and off-the-job search is large enough. In fact, as has been documented by Krueger and Muller (2010), the on the job search costs are strictly greater than searching while unemployed: just think about how much time a waitress or a management consultant working for $60+$ hours per week may be willing to devote for the on the job search. However, if we think of searching being costly in terms of money as opposed to time, one should not forget that going to an interview may require the worker to take one day off (or even more in case of remote destinations or a series of interviews for more qualified jobs). Consequently, apart from the lost output due to worker's absence, it 
seems also possible that an active on the job search may trigger e.g. lower worker output or loss of employer's trust. This phenomenon could be captured by a higher firing rate while doing on the job search translating into higher wage income risk and so into higher monetary search costs. Interestingly, such cases of firings upon the loss of trust have been documented ${ }^{18}$ in interviews ran by Bewley (1999).

Importantly, the data supports the mechanism at the core of this paper. The variance of the aforementioned quit rate in the US is significant: the quit rate in government sector amounted to only $0.7 \%$ while in retail sector it was already $2.9 \%$ and in food services even 4\%. Unsurprisingly then, as mentioned in the literature review, there is some empirical analysis documenting existence of the type of opportunistic worker behavior analyzed here.

Finally, given that the model-implied quit rate of $0.68 \%$ is already slightly below the one in the data, introducing the on the job search would reduce it even further and so lead to unclear conclusions. Thus, assuming away the on the job search should not be seen as critical for the results obtained.

\subsection{Empirical Observations vs the Model}

The labor markets in Continental Western Europe and the United States have been at odds in many features for many years so far. First of all, since 1980s the unemployment rate for the EU-15 countries has been persistently ${ }^{19}$ higher than in the US by $1 \%$ to $4.5 \%$, depending on the time period. Secondly, since mid-1980s income inequality in the US has risen much faster than in Europe and since then has been persistently higher. Thirdly, Manacorda and Petrongolo (1999) show that although the unemployment rate is a more pressing problem in the Continental Europe, its labor market mismatch levels have not increased as much as in the US. Finally, the increase in European unemployment rate has been accompanied by decreasing rates of exit from unemployment resulting in longer duration of unemployment spells and increase in the number of long-term unemployed.

As documented by Venn (2012), the unemployment insurance systems with and without benefit entitlement for workers quitting voluntarily are characteristic for many countries in Europe and the US, respectively. The model presented above abstracts from many important factors that could be equally likely to contribute to the differences in

\footnotetext{
${ }^{18}$ These cases might be partially captured by the $5.6 \%$ of active on the job searchers being unemployed in the dataset of Fallick and Fleischman.

${ }^{19}$ The only exception was the unemployment rate in 2010 when the two got close to each other for short period of time but then diverged again.
} 
the US and European labor markets and focuses solely on entitlement to benefits for quitters in order to find whether it may explain at least some of the empirical evidence.

As I have shown, the model is able to somehow reconcile the first three observations. The mechanism employed in the model leads to a higher unemployment rate. Also, following the benefit entitlement policy for workers quitting jobs voluntarily (Europe) is associated with 1) a lower income inequality, and 2) a higher match quality, as compared to the case of US status-quo. Nevertheless, although the associated with the optimal policy unemployment duration is higher in the separable search costs model, it is lower in the non-separable one.

Importantly, mind that the model has been calibrated solely to the US labor market which obviously has different fundamentals than the European. Moreover, characteristics of the latter differ a lot between individual countries. With this being said, the effects exposed by the model may very well be exacerbated by other institutional differences among the continents such as e.g. longer UI duration, more unionization or more stringent Employment Protection Legislation in the Continental Europe. In other words, this paper is identifying the direction of effects driving the economy associated with particular policies and does not aim at trying to investigate whether the differences in policies may account for the observed labor market discrepancies. Given this and other important economic factors not included in the model, the prevalent in Europe policy of paying benefits after voluntary quits may account for some but obviously not all of the observed differences in unemployment rates, match quality and income inequality.

Finally, there is a vast literature discussing reasons for the observed difference in characteristics of the US and European labor markets. A good review of possible explanations is provided by Bertola and Ichino (1995). Thomas Sargent and Lars Ljungqvist ran a major research program that aimed at identifying the reasons of these differences. Their theory is that generous European welfare system combined with a permanent change in the microeconomic labor conditions led to a sustained and high unemployment rate in Europe. Although the model presented here also attributes the observed discrepancies to generous welfare systems, it points exactly at one particular policy which may be partially responsible for the observed divergence of labor markets. Moreover, it also shows that economists should not only investigate the reasons of these observations, but also look at their consequences (e.g. in welfare terms). It might well be the case that the higher unemployment rate in Europe does not necessarily represent a huge waste of human resources and welfare, but to the contrary allows for a better 
allocation. To fully address this question, economists need more comprehensive models taking relevant general equilibrium effects into account.

\section{Concluding Discussion}

In this paper, I study a labor model with random search, unemployment insurance, savings, voluntary quits and various labor attachment requirements. In particular, I look for the optimal unemployment re-entitlement policy for quitters. In order to do this, I embark upon the method accounting for all the benefits and adverse effects generated by the policy, i.e. the social welfare analysis.

The model is calibrated to the US labor market where quitters are not entitled to UI. The results raise the question about the observed quitter-related UI policies differing from country to country and suggest that they may be rather ad hoc and may be a source of welfare inefficiencies. In particular, upon following the generous entitlement policy the implied welfare, unemployment rate and match quality are higher and both the pre- and after-tax income inequality are lower than in the case of no-entitlement for quitters. Interestingly, given that in Europe quitters are often eligible for UI, the model with its results identifies a concrete policy that could partially explain the divergence of the US and European labor markets.

The intuition for the results is two-fold. Firstly, the policy is insuring the income risk associated with a voluntary quit and although it increases the mass of quitters (and so the required tax rate to fund the UI), it improves the allocation of workers in the economy. Secondly, by increasing the non-wage value of low paid jobs, the policy lowers reservation wages of long term unemployed and so extracts some of them back into employment.

I find the results in this paper complementary to the literature discussed. First of all, worker's opportunism was found in Hopenhayn and Nicolini (2009). I show that allowing for this opportunistic and seemingly inefficient behavior of workers quitting jobs in order to find a better one may lead to significant long run welfare gains. Furthermore, I investigate the consequences of the unexplored assumption of monetary search costs. It turns out that this assumption is capable of generating search behavior in line with the one documented in the empirical literature. What is more, the model generates testable implications about differences in search behavior, and so in labor market outcomes for similar workers differing only with respect to their financial wealth. Thirdly, this paper fills an important gap in the UI literature by analyzing 
welfare consequences of entitlement to benefits for quitters. Finally, the results presented here hint at the need of new direction of economic research concentrated on (1) studying fully optimal UI design taking into account the possibility of endogenous quits (given how powerful this mechanism seems to be); (2) the relevance of monetary costs and substitutability between time and money for job search and (3) the welfare consequences of unemployment and thus, among others, of the divergence of the US and European labor markets.

Importantly, the model performs well not only in directions in which it has been calibrated but also others like implying realistic UI tax rates, unemployment duration, significant income inequality and generating realistic reservation wage behavior and endogenous quits after spending some time on the job (even without entitlement for quitters). The model lends itself easily to extensions like more involved and realistic eligibility criteria (for example labor attachment requirement for fired workers), sanctions (suspension periods for quitters), monitoring (penalties for insufficient search effort) and endogenizing wage distribution. 


\section{Acknowledgments}

My thanks are due to Arpad Abraham, Pavel Brendler, Melvyn Coles, Ramon Marimon, Juan Pablo Nicolini, Franz Ostrizek, Krzysztof Pytka, Michael Reiter, Dominik Sachs, Uwe Sunde and to two anonymous referees.

Funding: I benefited from the financial support for graduate students at the Institute for Advanced Studies in Vienna and European University Institute in Florence. 


\section{References}

[1] Aguiar, M., Hurst, E. and Karabarbounis, L., "Time Use During the Great Recession," American Economic Review, 103 (2013), 1664-1696.

[2] Abdulkadiroglu, A., Kuruscu, B. and Sahin, A., "Unemployment Insurance and the Role of Self-Insurance," Review of Economic Dynamics, 5 (2002), 681-703.

[3] Acemoglu, D., and Shimer, R., "Efficient Unemployment Insurance," Journal of Political Economy, 107 (1999), 893-928.

[4] Baker, M., and Rea, S., "Employment Spells and Unemployment Insurance Eligibility Requirements," Review of Economics and Statistics, 80 (1998), 80-94.

[5] Bertola, G., and Ichino, A. "Wage Inequality and Unemployment: United States versus Europe," NBER Macroeconomics Annual, 10 (1995), 13-66.

[6] Bewley, T., "Why Wages Don't Fall During a Recession," Harvard University Press (1999).

[7] Blau, D., and Robins, P., "Job Search Outcomes for the Employed and Unemployed," Journal of Political Economy, 98 (1990), 637-655.

[8] Burdett, K. "Unemployment Insurance Payments as a Search Subsidy: A Theoretical Analysis," Economic Inquiry, 42 (2008), 333-343.

[9] Card, D., Chetty, R. and Weber, A., "The Spike at Benefit Exhaustion: Leaving the Unemployment System or Starting a New Job?," American Economic Review, 97 (2007), 113-118.

[10] Chetty, R., "Moral Hazard versus Liquidity and Optimal Unemployment Insurance," Journal of Political Economy, 116 (2008), 173-234.

[11] Christofides, L. and McKenna, C., "Unemployment Insurance and Job Duration in Canada," Journal of Labor Economics, 14 (1996), 286-311.

[12] Faberman, J. and Kudlyak, M., "The Intensity of Job Search and Search Duration," Federal Reserve Bank of Richmond, Working Paper No. 14-12, (2016).

[13] Fallick, B. and Fleischman, C. A., "Employer-to-Employer Flows in the U.S. Labor Market: The Complete Picture of Gross Worker Flows," Federal Reserve Board Discussion Paper, (2004). 
[14] Feldstein, M., "Temporary Layoffs in the Theory of Unemployment," Journal of Political Economy, 84 (1976), 937-958.

[15] Green, D., and Riddell, C., "Qualifying for Unemployment Insurance: An Empirical Analysis," Economic Journal, 107 (1997), 67-83.

[16] Gruber, J., "The Wealth of the Unemployed," Industrial and Labor Relations Review, 55 (2001), 79-94.

[17] Hall, R., and Milgrom, P., "The Limited Influence of Unemployment on the Wage Bargain," American Economic Review, 98 (2008), 1653-1674.

[18] Hall, R., and Mueller, A., "Wage Dispersion and Search Behavior," NBER Working Paper, 2015.

[19] Henchman, J., "Unemployment Insurance Taxes: Options for Program Design and Insolvent Trust Funds," Tax Foundation Background Paper, 61 (2011), 1653-1674.

[20] Hopenhayn, H., and Nicolini, J., "Optimal Unemployment Insurance and Employment History," Review of Economic Studies, 76 (2009), 1049-1070.

[21] Hornstein, A., Krusell, P. and Violante, G., "Frictional Wage Dispersion in Search Models: A Quantitative Assessment," American Economic Review, 101 (2011), 2873-2898.

[22] Jones, S. "Job Search Methods, Intensity and Effects," Oxford Bulletin of Economics and Statistics, 51 (1989), 277-296.

[23] Jurajda, S., "Estimating the effect of unemployment insurance compensation on the labor market histories of displaced workers," Journal of Econometrics, 108 (2002), 227-252.

[24] Kitao, S., Ljungqvist, L. and Sargent, T., "A Life-Cycle Model of Trans-Atlantic Employment Experiences," working paper, (2015).

[25] Krueger, A., and Mueller, A., "Job search and unemployment insurance: New evidence from time use data," Journal of Public Economics, 94 (2010), 298-307.

[26] Krueger, A., and Mueller, A., "A Contribution to the Empirics of Reservation Wages," NBER Working Paper No. 19870, 2014. 
[27] Manacorda, M., and Petrongolo, B., "Skill Mismatch and Unemployment in OECD Countries," Economica, 66 (1999), 181-207.

[28] Marimon, R., and Zilibotti, F., "Unemployment vs. Mismatch of Talents: Reconsidering Unemployment Benefits," Economic Journal, 109 (1999), 266-291.

[29] McGrattan, E. R., and Prescott, E. C., "Taxes, Regulations, and the Value of U.S. and U.K. Corporations," Review of Economic Studies, 72 (2005), 767-796.

[30] Moffit, R., "Welfare Programs and Labor Supply", Handbook of Public Economics, in: A. J. Auerbach \& M. Feldstein (ed.), 4 (2002), Edition 1, 2393-2430.

[31] Pavoni, N. and Violante, G., "Optimal Welfare-to-Work Programs," Review of Economic Studies, 74 (2007), 283-318.

[32] Sargent, T., and Ljungqvist L., "The European Unemployment Dilemma," Journal of Political Economy, 106 (1998), 514-550.

[33] Shavell, S., and Weiss, L., "The Optimal Payment of Unemployment Insurance Benefits over Time," Journal of Political Economy, 87 (1979), 1347-1362.

[34] Shimer, R., and Werning, I., "Reservation Wages and Unemployment Insurance," Quarterly Journal of Economics, 122 (2007), 1145-1185.

[35] Tatsiramos, K., "Unemployment Insurance in Europe: Unemployment Duration and Subsequent Employment Stability," Journal of the European Economic Association, 7 (2009), 1225-1260.

[36] Venn, D., "Eligibility Criteria for Unemployment Benefits: Quantitative Indicators for OECD and EU Countries," OECD Social, Employment and Migration Working Paper No. 131, 2012.

[37] Wadsworth, J., "Unemployment Benefits and Search Effort in the UK Labour Market," Economica, 58 (1991), 17-34.

[38] Werning, I., Repeated Moral-Hazard with Unmonitored Wealth: A Recursive FirstOrder Approach, MIT Working Paper, 2001. 


\section{Appendix A: Proof of the reservation wage property}

Existence of such a reservation wage $\bar{w}(a, t, w)$ follows by the fact that being unemployed is associated with a continuation value which (given the distribution on wage draws) entails expectation about the wage draws in the future. If the wage draw today is low, then the value of declining it and being unemployed until tomorrow may yield greater value to the worker as the draw tomorrow is higher in expectation. Thus, it is optimal for the worker to decline such a wage offer. Note that, since I consider only benefits which are strictly smaller than recent wage and there is no disutility of working, there always exists a wage $w$ in the support of wage distribution which the worker is willing to accept. By continuity there exists at least one wage at which the worker is indifferent between accepting and rejecting a job offer. Let me denote this value by $\bar{w}(a, t, w)$.

It remains to show that the gain from accepting a job is monotonic in the offered wage, and thus for $w^{\prime} \geq \bar{w}$ it holds that $V_{e}\left(a, 1, w^{\prime}\right) \geq V_{e}(a, 1, \bar{w}(a, t, w))=V_{u}(a, t, w)$ and $V_{e}\left(a, 1, w^{\prime}\right)<V_{u}(a, t, \bar{w}(a, t, w))$ for $w^{\prime}<\bar{w}$.

Note that due to the UI design, the value of being unemployed is clearly monotone in wage, i.e. $V_{u}\left(a, 1, w^{\prime}\right) \geq V_{u}(a, 1, w)$. By this and the fact that once accepted the wage is constant over the employment time until separated, it follows that the value of being employed $V_{e}$, which includes the value of being unemployed at some point in the future, is also monotone in wage, i.e. $V_{e}\left(a, 1, w^{\prime}\right) \geq V_{e}(a, 1, w)$ if and only if $w^{\prime}>w$. Therefore $V_{e}\left(a, 1, w^{\prime}\right) \geq V_{e}(a, 1, \bar{w}(a, t, w))=V_{u}(a, t, \bar{w}(t, w))$ for $w^{\prime} \geq w$ and

conversely $V_{e}\left(a, 1, w^{\prime}\right)<V_{u}(a, t, \bar{w}(a, t, w))$ for $w^{\prime}<\bar{w}$, where the monotonicity and definition of the reservation wage is used. This establishes the reservation property. 


\section{Appendix B: Figures with Results of the Separable Utility Model}

Figure VIII: Representative unemployed worker behavior with separable search costs
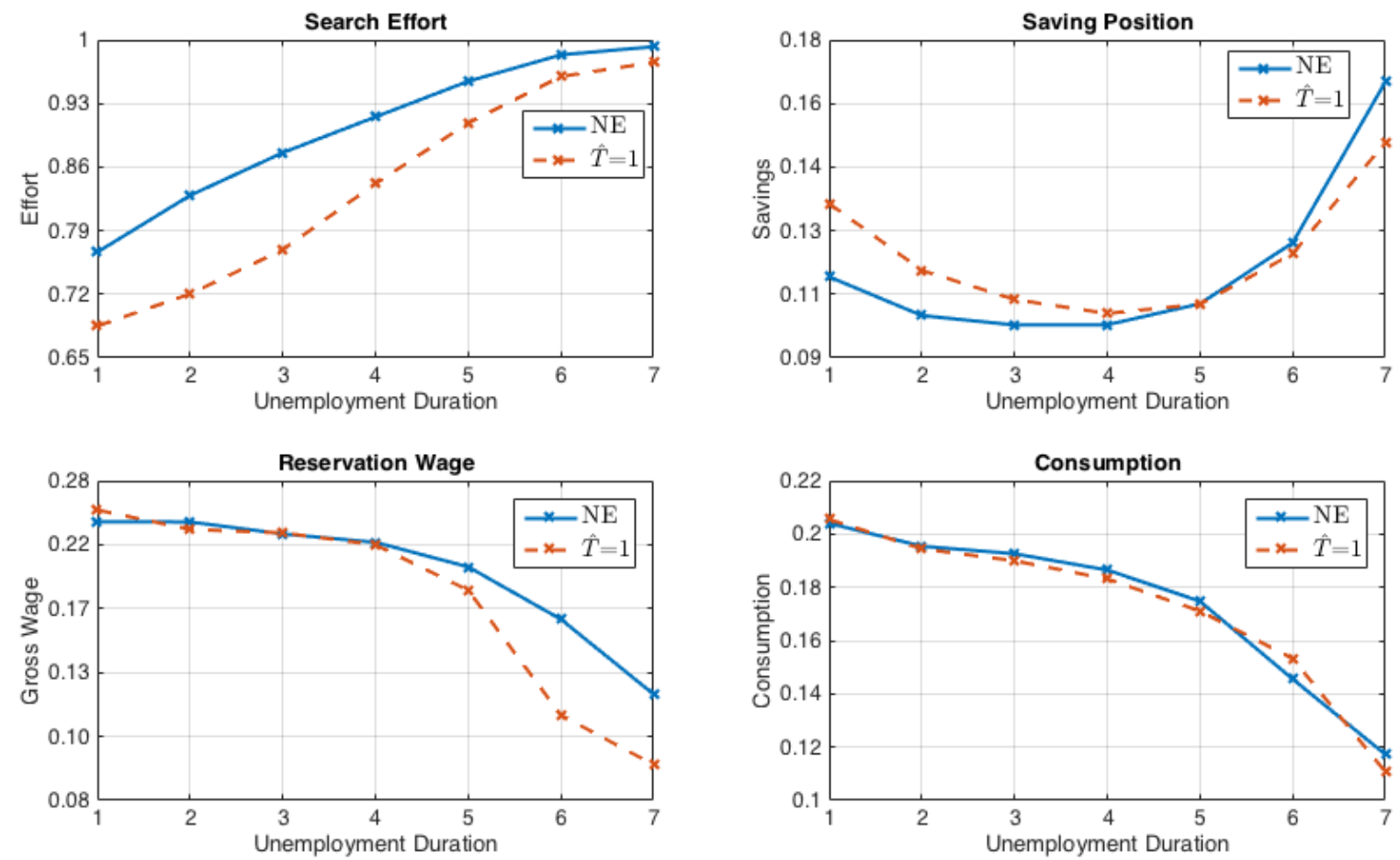

Notation: NE - no-entitlement, $\hat{T}=1$ - re-entitlement after 1 period on the job. 
Figure IX: Employed worker behavior with separable search costs
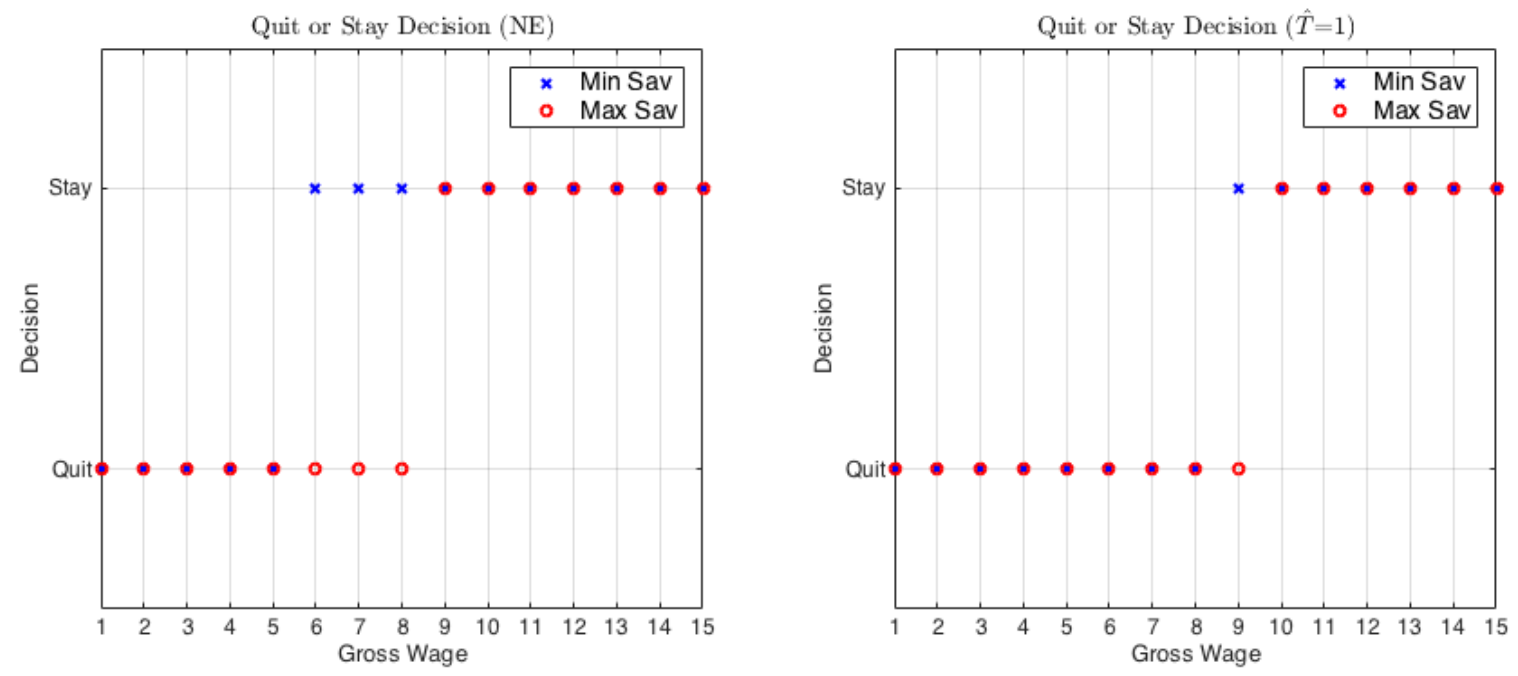

Notation: 1 stands for staying on the job, 0 for quitting; Min (Max) Sav - behavior of a worker with minimum (maximum) savings conditional on her current wage; NE - no-entitlement, $\hat{T}=1$ - re-entitlement after 1 period on the job.

Figure X: Behavior of representative poor and rich unemployed workers with separable search costs and no entitlement
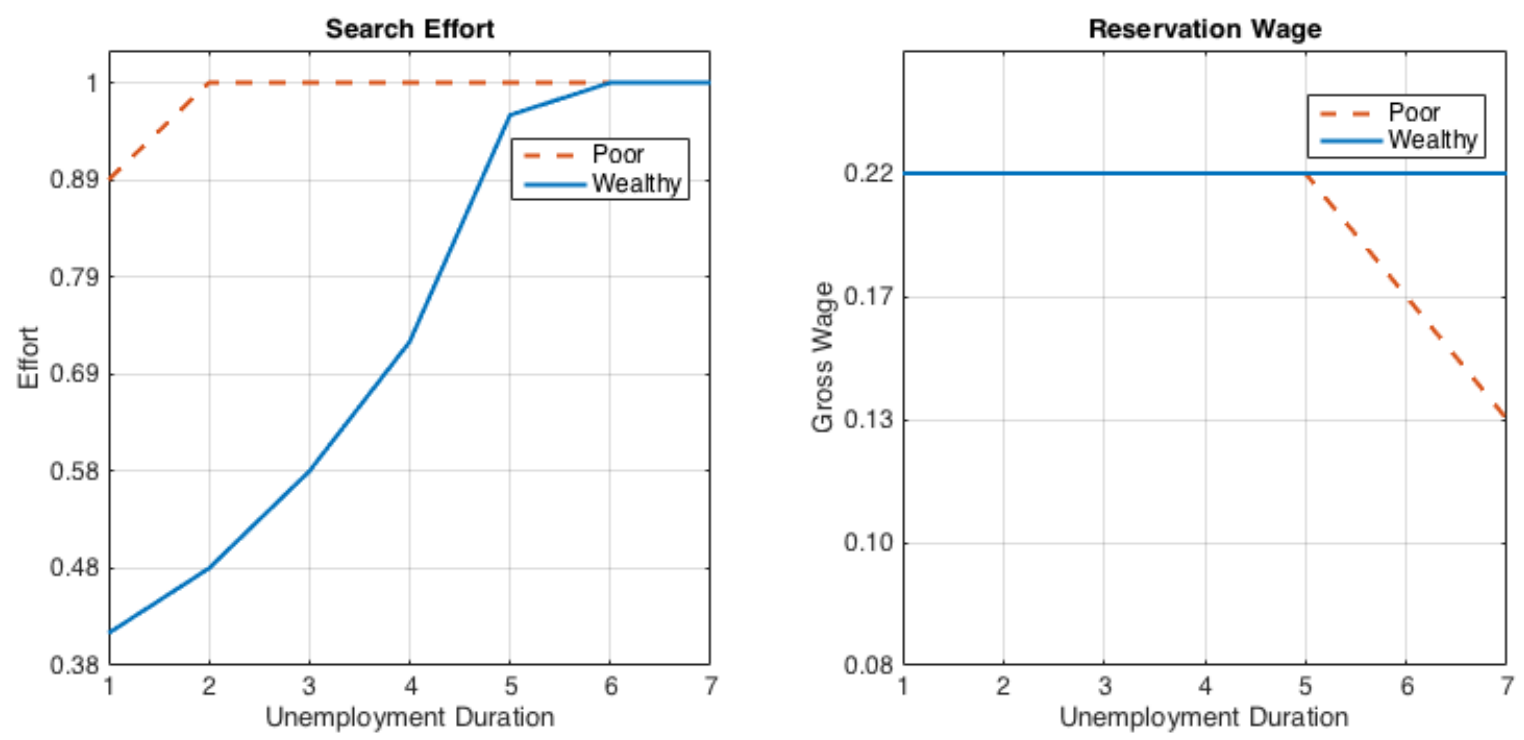

Notation: Poor - representative unemployed worker with $w=0.28$ and $a=0$; Wealthy representative unemployed worker with $w=0.28$ and $a=1.1$. 
Figure XI: Distribution of workers' savings and income with separable search costs
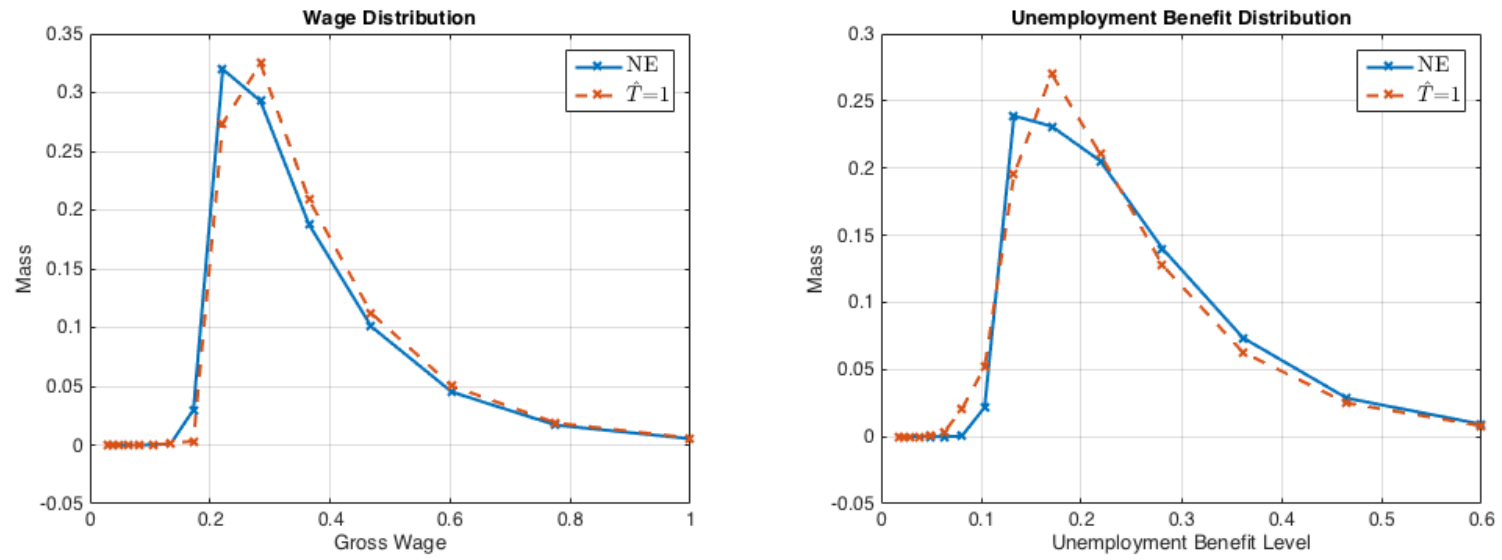

Notation: NE - no-entitlement; $\hat{T}=1$ - re-entitlement after 1 period on the job; Mass - a share of workers in a given category out of all employed or unemployed, respectively.

Figure XII: Breakdown of welfare gains with separable search costs
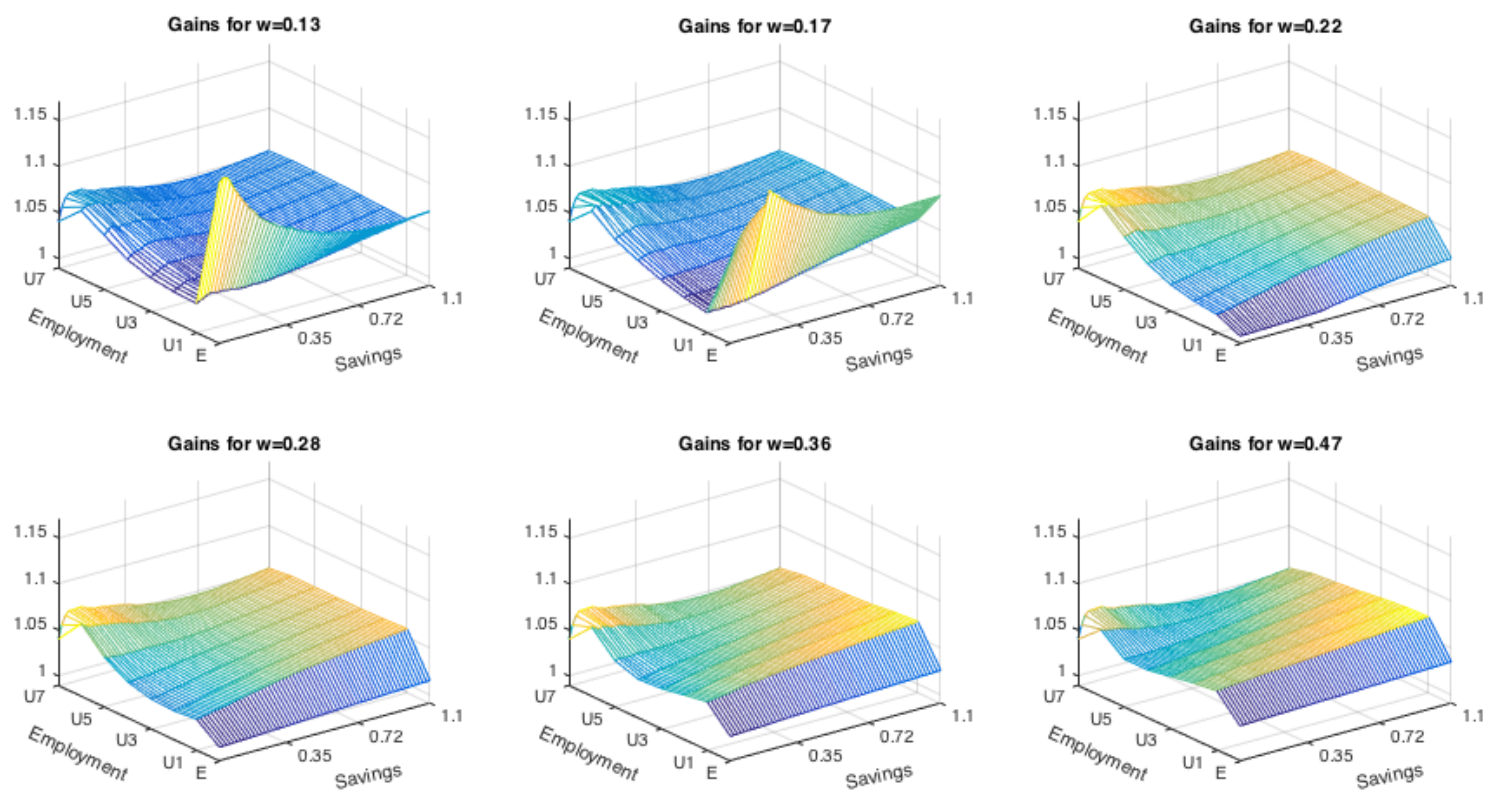

Notation: Employment state E stands for being currently employed; employment states U1 U7 stand for being either on UI (between 1 and 6) or on social assistance (state 7).

\section{Appendix C: Scenario Comparison}

In this Appendix, I perform a quasi comparative statics exercise in the model with monetary search costs. In order to do so, I solve the model for different values of a 
parameter of interest while holding everything else constant. Note that the purpose of this exercise is to perform a robustness check of the model's behavior and, in particular, not to find a fully optimal UI schedule (which goes beyond the scope of this paper). Importantly, due to very long computational time required, I solve here the re-calibrated mode $^{20}$ with hand-to-mouth workers. Table $\mathrm{V}$ provides results of this exercise, i.e. the qualitative total effects of changes in the level of replacement ratio and the length of unemployment benefits payments on reservation wages, search effort, unemployment rate, tax rate, welfare and inequality.

Consider first the effect of an increase in the replacement ratio ${ }^{21} \gamma$. As unemployed workers receive higher benefits, they become more picky about the jobs they are willing to accept - firstly due to the outside option having a relatively higher value, and secondly due to having possibility of exercising higher search effort and effectively facing a better wage distribution.

Furthermore, the average search effort goes up. The main reason for it is the assumed here monetary cost of search - as more resources are available to search-constrained workers, they take advantage of it in order to escape the unemployment state and the prospect of falling into the unemployment lock-in after benefit exhaustion. However, once the tax rate needed to finance the reform but its effect is less significant. This comparative statics finding is to the contrary of standard findings in literature as e.g. in Shavell and Weiss (1979), where with a separable utility there was no binding search constraint and so higher benefits reduced the gap between the values of employment and unemployment and thus lowered the search effort. The separable utility version of my model confirms its robustness by replicating this standard observation (not shown in the table).

Although the average search effort increases, the reservation wage increase dominates and so the unemployment rate goes up. This implies a higher tax rate needed to balance the government budget. This implies that the welfare will be hump-shaped: when $\gamma$ is too high, the welfare improving effects associated with better the match quality are dominated by the welfare abuse.

Similarly, the inequality is also hump-shaped: for $\gamma$ small enough, the increase in the replacement ratio and the tax rate bring the income from unemployment benefits closer to the wage income and so the inequality in the economy decreases. However, once $\gamma$ is large enough, although more workers access the top-paying jobs, the distribution of

\footnotetext{
${ }^{20}$ This alternative calibration is obviously targeting the same moments (apart from the saving moments) as the model with savings. For space saving reasons, I do not discuss its details here.

${ }^{21}$ Obviously, I assume that $\gamma \in[0,1]$.
} 
Table V: Scenario comparison

\begin{tabular}{ccccccc}
\cline { 2 - 6 } & $\mathrm{d} \bar{w}$ & $\mathrm{~d} q$ & $\mathrm{~d} U$ & $\mathrm{~d} \tau$ & $\mathrm{d}$ Welfare & $\mathrm{d}$ Inequality \\
\hline $\mathrm{d} \gamma$ & + & + & + & + & $?$ & $?$ \\
\hline $\mathrm{d} T$ & + & - & + & + & $?$ & $?$
\end{tabular}

Note: Table shows scenario comparison of total changes in key statistics on impact of change in parameters

employees across lower wage categories does not change much leading to a net increase in inequality.

Consequently, the welfare is maximized at $\gamma=78 \%$. The associated unemployment rate increases from $7.10 \%$ to $8.62 \%$, the tax rate almost doubles going up from $4.09 \%$ to $8.01 \%$ and the Gini coefficient goes down from $17.55 \%$ and $17.41 \%$ to $16.43 \%$ and $16.33 \%$, respectively for pre- and after-tax.

As the length of the benefit entitlement period is increased, workers stick longer to their initial reservation wage (which is the highest over the unemployment spell) and so the average reservation wage goes up. Moreover, given that workers expect to receive the UI for longer, the average search effort declines. As a result, the unemployment rate increases. For similar reasons as above, the tax rate on employed workers increases. However, the effect on inequality is ambiguous. For $T$ low enough, the relationship between inequality and this parameter is negative - higher tax rate on employed reduces net wage income and redistributes it to the unemployed. However, once $T$ is large enough this relationship is no longer clear for reasons similar to the ones discussed above.

Similarly as above, the impact on inequality is hump-shaped. As the entitlement gets longer, the policy saves more people from entering the social assistance state and so the inequality is reduced. However, above some high value of $T$ these effects become much smaller and so further increases in $T$ start increasing the inequality.

Consequently, the welfare is maximized with UI entitlement for 1 year. The associated unemployment rate increases from $7.10 \%$ to $10.09 \%$, the tax rate goes up from $4.09 \%$ to $7.26 \%$, the Gini coefficient goes down from $17.55 \%$ and $17.41 \%$ to $16.53 \%$ and $16.24 \%$, respectively for pre- and after-tax. 


\section{Appendix D: Computation method}

The model is solved numerically for a steady state equilibrium. In order to do this, I use an iterative method of successive approximations. First a policy parameter $\hat{T}$ is chosen and a tax rate $\tau$ is guessed. Given the two, value function iteration is used to solve the functional equations (1) and (2) for optimal choices of consumption, saving, search effort, reservation wages and quit decisions. Next, the invariant distribution $G^{*}$ is computed using a transition matrix $\Gamma$ for given optimal decisions. Finally, the invariant distribution is used to evaluate the government budget balance. If it is significantly different from zero, a bisection method is used to bracket the root and the steps described are repeated until an equilibrium is found.

In order to solve for optimal decision rules, I use the standard technique of dynamic programming for infinite horizon case. The first step involves discretizing the action space by choosing a grid of feasible search efforts and saving decisions: it is chosen sufficiently fine such that adding more grid points does not affect the results. Thus, given the description of the model above, the whole model is discretized. Then, optimal decision rules for each state are computed by starting with an initial approximation of the value function in (2) and computes the right hand side of it in order to obtain a subsequent approximation. This procedure is repeated until convergence of the value function is achieved.

\section{Appendix E: Markov transition function}

Given the model, the worker's employment opportunities state, $s$, follows a $n \times A_{M} \times$ $(\hat{T}+T+1)$-state Markov chain. If $s=\left\{u, a, t, w_{i}\right\} i \in\{1,2, \ldots, n\}$, she remains unemployed for that period, receives unemployment benefit according to the benefit payment path (pinned down by $t$ and $w_{i}$ ), has savings $a$ and may receive a wage offer $w^{\prime}$ after setting the optimal search effort $q_{t}$. After having received a wage offer she makes a decision about her reservation wage $\bar{w}$ and thus pins down her transition probabilities to states tomorrow. Furthermore, she can be employed on a job with the one of the $n$ possible wages: if $s=\left\{e, a, t, w_{i}\right\}$ she is still employed and has worked for a wage $w_{i}$ for $t$ periods so far. While on the job, based on comparison of $V_{u}$ and $V_{e}$, the worker makes a decision about quitting the job or staying in it which determines her transition probabilities to other states in the next period.

Therefore, the transition function for the employment opportunities state given 
worker's decision function is a $\left[A_{M} \cdot n \cdot(\hat{T}+T+1)\right] \times\left[A_{M} \cdot n \cdot(\hat{T}+T+1)\right]$ matrix $\Gamma=\left[\Gamma_{i j}\right]$, where $i, j \in\left\{1,2, \ldots, A_{M} \cdot n \cdot(\hat{T}+T+1)\right\}$.

For instance, $\Gamma_{\hat{T}+1,2(\hat{T}+T+1)+1}=\mathbb{P}\left\{s_{t+1}=\left\{e, 0,1, w_{3}\right\} \mid s_{t}=\left\{u, 0,1, w_{1}\right\}\right\}$ is the transition probability to employment with wage $w_{3}$ and 0 assets conditional on being unemployed for 1 period, receiving unemployment benefits tied to the most recent wage $w_{1}$ and having 0 assets. As there is no on the job search, the effort exerted will only affect probabilities of transition from unemployment to employment. Figure XIII presents example of transition probabilities for unemployed and employed workers.

Figure XIII: Transition function for workers in states $\left\{u, a, t, w_{i}\right\}$ and $\left\{e, a, t, w_{j}\right\}$

\begin{tabular}{|c|c|c|c|c|c|c|}
\hline State & $\left\{u, a^{\prime}, t^{\prime}, w_{i}\right\}$ & & $\left\{e, a^{\prime}, t^{\dagger}\right.$ & $\left.w_{1}\right\}$ & $\left\{e, a^{\prime}, t^{\dagger}\right.$, & $\left.w_{n}\right\}$ \\
\hline$\left\{u, a, t, w_{i}\right\}$ & $1-f\left(q_{t}\right) \sum_{w \geq \bar{w}} \mathbb{P}(w)$ & & $\left(q_{t}\right) \mathbb{P}\left(w_{1}\right)$ & $\begin{array}{l}w_{1} \geq \bar{w} \\
\text { otherwise }\end{array}$ & $\left\{\begin{array}{l}f\left(q_{t}\right) \mathbb{P}\left(w_{n}\right) \\
0\end{array}\right.$ & $\begin{array}{l}w_{n} \geq \bar{w} \\
\text { otherwise }\end{array}$ \\
\hline$\left\{e, a, t, w_{1}\right\}$ & $\left\{\begin{array}{ll}1 & V_{u}\left(a^{\prime}, t^{\prime}, w_{1}\right)>V_{e}\left(a^{\prime}, t^{\dagger}, w_{1}\right) \\
\sigma & \text { otherwise }\end{array}\right\}$ & $\left\{\begin{array}{l}0 \\
1-\sigma\end{array}\right.$ & \multicolumn{2}{|c|}{$\begin{array}{l}V_{u}\left(a^{\prime}, t^{\prime}, w_{1}\right)>V_{e}\left(a^{\prime}, t^{\dagger}, w_{1}\right) \\
\text { otherwise }\end{array}$} & \multicolumn{2}{|l|}{0} \\
\hline$\vdots$ & $\vdots$ & \multicolumn{3}{|c|}{$\vdots$} & \multicolumn{2}{|l|}{$\vdots$} \\
\hline$\left\{e, a, t, w_{n}\right\}$ & $\begin{cases}1 & V_{u}\left(a^{\prime}, t^{\prime}, w_{n}\right)>V_{e}\left(a^{\prime}, t^{\dagger}, w_{n}\right) \\
\sigma & \text { otherwise }\end{cases}$ & & 0 & & $\begin{array}{ll}0 & V_{u}\left(a^{\prime}, t^{\prime}\right. \\
1-\sigma & \text { otherwi }\end{array}$ & $\begin{array}{l}\left(w_{n}\right)>V_{e} \\
s e\end{array}$ \\
\hline
\end{tabular}

Note: Each row contains probability of transition from current row-state to a possible column-state. Notice that the agents make a decision about the state $a^{\prime}$ so all the transition probabilities are conditional on the decision $a^{\prime}$ being optimal in a given state. Notation: $\left\{e, a, t, w_{i}\right\}$ - employed for $t$ periods at wage $w_{i}$ with savings $a,\left\{u, a, t, w_{i}\right\}$ unemployed for $t$ periods so far, having the most recent wage $w_{i}$ and savings $a$. Also:

$$
t^{\dagger}=\left\{\begin{array}{ll}
\min \{\hat{T}, t+1\} & \text { if previously } x=e \\
1 & \text { if previously } x=u
\end{array} \quad t^{\prime}= \begin{cases}1 & \text { if previously } x=e \text { and } t=\hat{T} \\
T+1 & \text { if previously } x=e \text { and } t<\hat{T} \\
\min \{T+1, t+1\} & \text { if previously } x=u\end{cases}\right.
$$

